\title{
Alcohol, marijuana, and tobacco use trajectories from age 12 to 24 years: Demographic correlates and young adult substance use problems
}

\author{
SARAH E. NELSON, ${ }^{a}$ MARK J. VAN RYZIN,${ }^{b}$ AND THOMAS J. DISHION ${ }^{b, c}$ \\ ${ }^{a}$ Harvard Medical School; ${ }^{b}$ University of Oregon Child and Family Center; and ${ }^{c}$ Arizona State University
}

\begin{abstract}
Substance use trajectories were examined from early adolescence to young adulthood among a diverse sample of 998 youths. Analysis of longitudinal data from ages 12 to 24 identified distinct trajectories for alcohol, marijuana, and tobacco use. Modeling revealed 8 alcohol, 7 marijuana, and 6 tobacco use trajectories. Analyses assessed risk for substance use problems in early adulthood within each trajectory, as well as overlap among alcohol, marijuana, and tobacco use trajectories. Findings confirmed that adolescents with early- and rapid-onset trajectories are particularly vulnerable to the development of problematic substance use in early adulthood. However, analyses also identified an escalating high school onset trajectory for alcohol and for marijuana use that was equally prognostic of problem use in adulthood. Moreover, tobacco use in early adolescence was associated with developing high-risk marijuana and alcohol use patterns. Random assignment to the Family Check-Up intervention was found to reduce risk for membership in the high-risk marijuana use trajectories, suggesting that family-based approaches delivered during adolescence can prevent escalations to problematic substance use. These findings suggest the importance of developmental heterogeneity and equifinality in considering prevention for alcohol and drug use.
\end{abstract}

Past research has shown that early substance use is a risk factor for later substance-related problems (Anthony, 1991; Robins \& Przybeck, 1985). Analysis of substance use trajectories, however, provides a more nuanced perspective on movement through substance use risk. Most of this past trajectory work, described later in this article, has been limited to the adolescent years and has not included information about the development of substance use problems in early adulthood. Our study was designed not only to model trajectories of substance use across adolescence (i.e., middle school, high school, and post-high school years) but also to examine the overlap between those trajectories and their relationship to young adult substance use problems.

Existing evidence suggests that use of alcohol, tobacco, and marijuana is heavier among youths who start early in ado-

This project was supported by Grant RAA016810A from the National Institute on Alcohol Abuse and Alcoholism (to S.E.N.), by Grants DA07031 and DA13773 from the National Institute on Drug Abuse and Grant AA12702 at the National Institute on Alcohol Abuse and Alcoholism (to T.J.D.), and by Grant T32 MH20012 from the National Institute of Mental Health (to M.J.V.R.). The authors extend special thanks to the Project Alliance staff, the Portland Public School District, the Child and Family Center data team, and the participating youth and families. The first two authors (S.E.N. and M.V.R.) had full access to all of the data in the study and take responsibility for the integrity of the data and the accuracy of the data analysis.

Address correspondence and reprint requests to: Sarah E. Nelson, Division on Addiction, Cambridge Health Alliance, Harvard Medical School, 101 Station Landing, Medford, MA 02155; E-mail: snelson@hms.harvard.edu. lescence. Children who have used alcohol by Grade 7 exhibit more and heavier substance use (alcohol, illicit drugs, and tobacco), are more likely to have substance use problems, and are more likely to exhibit criminal behavior in both late high school and young adulthood than are those who have not used by Grade 7 (Ellickson, Tucker, \& Klein, 2003). Early alcohol or tobacco use also relates to later use of illicit drugs (Kandel, Yamaguchi, \& Chen, 1992). Among people who use illicit drugs, the earlier they initiated use, the more likely they are to demonstrate drug abuse or drug dependence (Grant \& Dawson, 1998). Similarly, early-adolescence alcohol use initiation corresponds to greatly increased risk for alcohol misuse (Hawkins et al., 1997) and alcohol use disorders (DeWit, Adlaf, Offord, \& Ogborne, 2000).

Multiple mechanisms have been proposed through which early substance use initiation influences later substance use problems. The majority of these fall into two categories. In one, early substance use is a marker of an underlying vulnerability (genetic, environmental, or both) that continues to influence behavior as an individual develops. For example, impulse control problems and problems with emotion regulation predict a host of harmful behaviors, from early substance use initiation to excessive substance use to deviant and criminal behavior (Mezzich et al., 2007; Tarter et al., 2003). Problem behavior theory posits an underlying susceptibility to a range of problem behaviors but specifies interactions between personlevel vulnerabilities and the social environments in creating that susceptibility (Jessor, 1987; Jessor \& Jessor, 1977). The 
second category involves proposed mechanisms through which the early initiation of substance use itself is a direct influence on future substance use and type of future substance use. Gateway hypotheses (e.g., Cleveland \& Wiebe, 2008; Kandel et al., 1992) fall into this category, as do theories in which early substance use creates an interpersonal context in which youths self-organize into substance-using friendships, which in turn lead to more opportunities to use substances and to engage in multiple problem behaviors and establish deviant norms (e.g., Dishion, Nelson, \& Bullock, 2004; Dishion \& Owen, 2002).

Despite the wealth of research about early substance use initiation, fewer studies have examined the relationship between these behaviors at the time of early initiation. These relationships are important for understanding and testing the mechanisms previously described, that is, understanding whether youths who initiate one substance early are at greater risk of initiating the use of other substances, and whether certain substance use appears to be a prerequisite for other substance use. The Monitoring the Future study, which collects information about the substance use of a nationally representative sample of students in Grades 8, 10, and 12 each year, consistently finds that alcohol is the most commonly used substance (more than $50 \%$ of Grade 8 students have tried it, and more than $20 \%$ have used it in the past 30 days), followed by tobacco $(>45 \%$, $>18 \%)$, then marijuana $(>20 \%, 10 \%)$ and inhalants $(>19 \%$, $>5 \%$ ), with other illicit drugs having a much lower prevalence of use (Wallace et al., 2003). However, these numbers do not tell us about the overlap among these behaviors.

Research consistently shows a relationship between substance use of all kinds and other problem behaviors, as well as their predictors (Barnes, Welte, Hoffman, \& Dintcheff, 2005; Jessor, 1987; Komro, Tobler, Maldonado-Molina, \& Perry, 2010). In terms of the specific relationship (causal or otherwise) between initiation of different forms of substance use, the findings are mixed. Alcohol and tobacco use appear to influence each other across time (Jackson, Sher, Cooper, \& Wood, 2002). In general, adolescents begin using alcohol and/or cigarettes prior to initiating marijuana use, and among those who progress further, marijuana use precedes use of other illicit substances (Ellickson, Hays, \& Bell, 1992; Kandel et al., 1992). Longitudinal study of this sequence also suggests that adolescents add substances rather than substitute them, continuing to use alcohol or marijuana when they initiate use of harder substances (Ellickson et al., 1992). However, one study of serious drug users suggests that only one third followed the typical sequence of substance use initiation, suggesting that the greatest risk might be willingness to use more serious substances early rather than substances such as alcohol, tobacco, or marijuana (Mackesy-Amiti, Fendrich, \& Goldstein, 1997).

The Mackesy-Amiti et al. (1997) study points to the importance of considering individual patterns of behavior across time. It may be those who deviate from the aggregated norm whose behavior is the most interesting in terms of risk and prevention. In addition, these individual patterns can shed more light on various pathways and mechanisms through which substance use problems develop.
There is clearly a need for a science of the development of substance use problems from adolescence to young adulthood. A description of typical developmental patterns that are both low and high risk will provide a scientific framework for thinking about atypical development. For example, it may be that early initiators can be divided into youths with strong underlying vulnerabilities for whom early initiation simply reflects the beginning of a cluster of problem behaviors set into motion by those vulnerabilities, and youths for whom the early initiation is more circumstantial. For the second group, pathways might further diverge into those whose initial substance experience leads to a predictable course of substance experimentation and those more resilient youths whose early initiation never progresses beyond low to moderate use.

\section{Trajectory Research}

Trajectory approaches facilitate examination of the multiple developmental courses of a behavior instead of average group levels at each time point. Trajectory modeling, which allows for nonlinear behavior progressions, can help empirically identify groups within a sample that evidence similar behavioral patterns across time. Applied to the study of the development of substance use and related problems, trajectory approaches help us identify different pathways through which individuals initiate, progress, and desist in their substance use, as well as the correlates, predictors, and outcomes of those pathways. Different trajectories, such as stable trajectories versus those that fluctuate, might indicate different etiological pathways toward the development of substance use problems (e.g., pathways similar to Type I and Type II conceptualizations of alcohol use disorders or Tarter and colleagues' description of nontransmissive vs. transmissive liability; Cloninger, Bohman, \& Sigvardsson, 1981; Tarter, Horner, \& Ridenour, 2012). For adolescents and young adults, shifts in trajectories (e.g., from stable use to escalation or from escalation to desistence) likely reflect critical periods either at the individual level (e.g., transition to a new school, parental divorce, or initiation into a new peer group) or, for common trajectories, at the societal level (e.g., transition from middle to high school; transition from high school to college; or assumption of adult roles, such as employment and family). These trajectory shifts also mark key time points for intervention. Past trajectory research is reviewed in the following subsections. Because this research has primarily involved single substances, each of these substances is addressed separately. However, understanding the overlap between substance use trajectories is essential for understanding the etiology of substance use problems; thus, the research to date on trajectory overlap is reviewed at the end of this section.

\section{Alcohol}

Trajectory research on the development of alcohol use in middle school and high school most often reveals trajectories of use that involve steep increases during the transition from middle school to high school, often in the first year of high 
school (Li, Barrera, Hops, \& Fisher, 2002; Li, Duncan, \& Hops, 2001). The number of trajectories found during this time period varies by method and measures, but most studies have found four to five. All these studies find a low- or nodrinking trajectory that remains stable throughout the middle school and high school years, a chronic trajectory that escalates quickly and then remains stably high, and a more gradually increasing trajectory. In all cases, the low/no drinking trajectories are the most common, followed by the gradual increasers, and the chronic pattern represents the smallest group (Chassin, Pitts, \& Prost, 2002; Colder, Campbell, Ruel, Richardson, \& Flay, 2002; Hill, White, Chung, Hawkins, \& Catalano, 2000; Martino, Ellickson, \& McCaffrey, 2009). Table 1 describes the findings of past trajectory work on alcohol, marijuana, and tobacco use.

Late adolescence and young adult alcohol use trajectory patterns are similar to those for middle and high school, though their distribution is different (e.g., more individuals fall into drinking trajectories and fewer fall into nondrinking trajectories). Again, as many as five trajectories emerge, and again they include a large low/no drinking group and a small rapidly escalating or chronically high-level group (Jackson \& Sher, 2005; Schulenberg, Wadsworth, O’Malley, Bachman, \& Johnston, 1996; Windle, Mun, \& Windle, 2005). The trajectories that fall between these two vary by study but tend to include a late-onset trajectory similar to that found in the middle and high school studies, but with drinking commencing during the transition from high school to young adulthood and then escalating. Multiple studies also have found a decreasing or U-shaped trajectory in these years that represents developmentally limited drinking patterns: adolescents or college-age students who drink heavily but then mature out of these heavy drinking patterns (Jackson \& Sher, 2005; Schulenberg et al., 1996; Windle et al., 2005).

Studies that have investigated drinking trajectories and young adult outcomes suggest that, as one might expect, individuals who drink chronically throughout middle school, high school, and young adulthood or who rapidly escalate their drinking behavior during these years are at the greatest risk of young adult substance use problems (Chassin et al., 2002; Colder et al., 2002; Hill et al., 2000). One surprising finding from Hill et al.'s (2000) study was that their group of late-onset rapid escalators had poorer substance use related outcomes than did the chronic group. It is not surprising that light drinkers and abstainers are at the least risk.

Overall, these studies suggest that there is significant heterogeneity in alcohol use patterns from adolescence through young adulthood and that this heterogeneity is to some extent predictive of alcohol use problems. Trajectories in the middle and high school years are characterized by different levels of escalation, whereas trajectories that follow individuals through their 20s begin to reflect patterns of desistance and reduction. Although there is a clear link between chronic trajectories and later substance use problems, very little research has successfully discriminated other trajectories of use from each other in terms of later consequences.

\section{Tobacco}

The most common tobacco use trajectory in middle school and high school, similar to alcohol, is no use throughout (Abroms, Simons-Morton, Haynie, \& Chen, 2005; Bernat, Erickson, Widome, Perry, \& Forster, 2008). Smoking trajectories during this time period mirror alcohol use trajectories, though studies tend to find more trajectories for smoking than for alcohol use. Multiple studies have found a rapidly escalating chronic use trajectory, similar to that for alcohol, and a later onset, more gradually escalating trajectory, also similar to that for alcohol use. Fewer than $10 \%$ of participants fell into the chronic trajectory during this time period, across studies (Abroms et al., 2005; Colder et al., 2001). Whereas the most common number of trajectories among alcohol use studies appears to be five, tobacco use studies tend to find six trajectories (Bernat et al., 2008; Colder et al., 2001). One of these is an experimenter trajectory in which individuals do not escalate their use but smoke occasionally throughout (Abroms et al., 2005; Bernat et al., 2008; Colder et al., 2001). Another is U-shaped, in which smoking begins to decrease in the late teen years (Bernat et al., 2008). Finally, some studies find additional escalating trajectories that escalate later than those of chronic users but either escalate more quickly than the late-onset, gradual trajectory or escalate to higher levels (Colder et al., 2001).

Several studies of smoking trajectories have extended their follow-up beyond high school and investigated trajectories from early adolescence through the early to mid-20s or even into the 30s. Again, these studies tend to find six trajectories (Chassin, Presson, Pitts, \& Sherman, 2000; Costello, Dierker, Jones, \& Rose, 2008; Lessov-Schlaggar et al., 2008; Maggi, 2008; Orlando, Tucker, Ellickson, \& Klein, 2004). The prevalence of the nonsmoking trajectory is slightly lower in these studies than in those involving only middle and high school, but it is still in the range of $30 \%$ to 50\% (Brook et al., 2008; Chassin et al., 2000; Costello et al., 2008; Lessov-Schlaggar et al., 2008; Maggi, 2008; Orlando et al., 2004; Riggs, Chou, Li, \& Pentz, 2007; White, Pandina, \& Chen, 2002). Studies that investigate smoking trajectories and young adult outcomes find that nonsmokers and experimenters experience fewer substance use problems as young adults than do others, and that early escalating and chronic smokers are at greater risk for drug use problems, in particular, than are others (Orlando et al., 2004).

Overall, tobacco use trajectories are similar to those for alcohol use, though there appears to be more heterogeneity in patterns, primarily accounted for by desistance patterns that begin earlier and a wider range of levels of smoking (e.g., variance in number of cigarettes smoked). Heavier and earlier use relates to later nicotine dependence, and early, chronic trajectories also appear to relate to later alcohol use and drug use problems.

\section{Marijuana}

Less research has been conducted on marijuana trajectories throughout adolescence. The studies that do exist have found 
Table 1. Summary of past substance use trajectory research

\begin{tabular}{|c|c|c|c|c|c|c|c|c|}
\hline Study & Substance & Trajectory Measure & $\begin{array}{l}\text { Traj. } \\
\text { Age } \\
\text { Range }\end{array}$ & $\begin{array}{l}\text { No of } \\
\text { Traj. }\end{array}$ & Prevalence of Trajectories & $\begin{array}{l}\text { Trajectory } \\
\text { Shapes }\end{array}$ & Outcomes & $\begin{array}{c}\text { Relationship Between Trajectory } \\
\text { and Outcome }\end{array}$ \\
\hline Li et al., 2001 & Alcohol & $\begin{array}{l}\text { Current use } \\
\text { frequency }\end{array}$ & $12-18$ & 2 & $\begin{array}{l}32 \% \text { high initial with } \\
\text { HS inc. } \\
68 \% \text { low initial with } \\
\text { MS \& HS inc. }\end{array}$ & & $\begin{array}{l}\text { Past 6-month alcohol, } \\
\text { cigarette, and } \\
\text { marijuana use } \\
\text { frequency at age } 19\end{array}$ & $\begin{array}{l}\text { High initial use trajectory had higher } \\
\text { age } 19 \text { substance use of all types } \\
\text { than low initial use trajectory }\end{array}$ \\
\hline Li et al., 2002 & Alcohol & $\begin{array}{l}\text { Past } 12 \text {-month } \\
\text { frequency }\end{array}$ & $14-18$ & 2 & $\begin{array}{l}35 \% \text { high with increase } \\
65 \% \text { low with increase }\end{array}$ & & NA & NA \\
\hline $\begin{array}{l}\text { Chassin et al., } \\
2002\end{array}$ & Alcohol & $\begin{array}{l}\text { Past 12-month } \\
\text { binge frequency }\end{array}$ & $12-23$ & 4 & $\begin{array}{l}40 \% \text { no binge } \\
21 \% \text { early heavy } \\
30 \% \text { late moderate } \\
10 \% \text { early infrequent }\end{array}$ & & $\begin{array}{l}\text { Past 5-year alcohol or } \\
\text { drug use disorder; past } \\
\text { 1-year anxiety or } \\
\text { depressive disorder at } \\
\text { age 18-23 }\end{array}$ & $\begin{array}{l}\text { Alcohol use disorder: Early heavy } \\
\text { trajectory }>\text { all others; No binge } \\
\text { trajectory }<\text { all others } \\
\text { Drug use disorder: No binge } \\
\text { trajectory }<\text { all others } \\
\text { Anxiety and depression: no } \\
\text { trajectory effects }\end{array}$ \\
\hline $\begin{array}{l}\text { Colder et al., } \\
2002\end{array}$ & Alcohol & $\begin{array}{l}\text { Past 30-day use } \\
\text { frequency \& } \\
\text { quantity }\end{array}$ & $12-18$ & 5 & $\begin{array}{l}46 \% \text { occasional very light } \\
36 \% \text { escalators } \\
9 \% \text { occasional heavy } \\
6 \% \text { rapid escalators } \\
1 \% \text { heavy decliners }\end{array}$ & & $\begin{array}{l}\text { Past } 12 \text {-month alcohol- } \\
\text { related consequences at } \\
\text { age } 18\end{array}$ & $\begin{array}{l}\text { Rapid escalators most likely to have } \\
\text { problems; all other trajectories } \\
\text { more likely to have problems than } \\
\text { occasional very light trajectory }\end{array}$ \\
\hline Hill et al., 2000 & Alcohol & $\begin{array}{l}\text { Past 30-day } \\
\text { binge frequency }\end{array}$ & $13-18$ & 4 & $\begin{array}{l}70 \% \text { no binge } \\
4 \% \text { increaser } \\
3 \% \text { early high } \\
23 \% \text { late onset }\end{array}$ & & $\begin{array}{l}\text { Alcohol or drug use } \\
\text { disorder; depression at } \\
\text { age } 21\end{array}$ & $\begin{array}{l}\text { Alcohol use disorder: increasers } \\
\text { most likely to have alcohol use } \\
\text { disorder } \\
\text { Depression: no trajectory effects }\end{array}$ \\
\hline $\begin{array}{l}\text { Martino et al., } \\
2009\end{array}$ & Alcohol & $\begin{array}{l}\text { Past 30-day } \\
\text { binge frequency }\end{array}$ & $14-19$ & 4 & $\begin{array}{l}64 \% \text { slow increasers } \\
24 \% \text { stable heavy } \\
7 \% \text { adolescent heavy } \\
6 \% \text { decreasers }\end{array}$ & & NA & NA \\
\hline $\begin{array}{l}\text { Jackson \& Sher, } \\
\quad 2005\end{array}$ & Alcohol & $\begin{array}{l}\text { Past 30-day } \\
\text { binge frequency; } \\
\text { past } 12 \text {-month } \\
\text { use frequency/ } \\
\text { quantity }\end{array}$ & $18-28$ & 4 & $\begin{array}{l}\text { Binge frequency } \\
60 \% \text { no binge } \\
19 \% \text { developmentally } \\
\text { limited } \\
19 \% \text { chronic } \\
2 \% \text { late onset } \\
\text { Use frequency } \\
45 \% \text { no use } \\
26 \% \text { developmentally } \\
\text { limited } \\
22 \% \text { chronic } \\
7 \% \text { late onset }\end{array}$ & & NA & NA \\
\hline
\end{tabular}




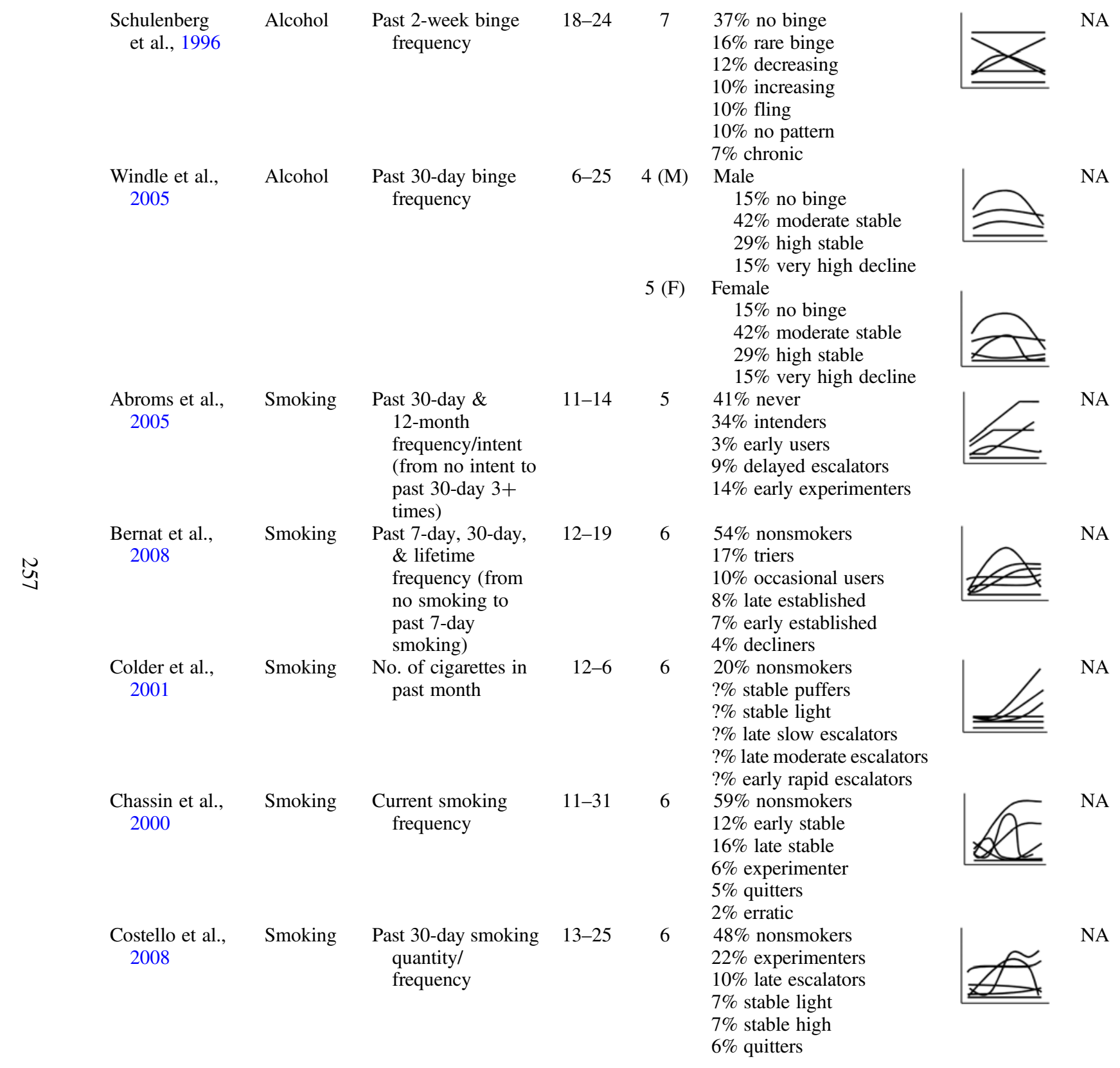


Table 1 (cont.)

\begin{tabular}{|c|c|c|c|c|c|c|c|c|}
\hline Study & Substance & Trajectory Measure & $\begin{array}{l}\text { Traj. } \\
\text { Age } \\
\text { Range }\end{array}$ & $\begin{array}{l}\text { No of } \\
\text { Traj. }\end{array}$ & Prevalence of Trajectories & $\begin{array}{l}\text { Trajectory } \\
\text { Shapes }\end{array}$ & Outcomes & $\begin{array}{c}\text { Relationship Between Trajectory } \\
\text { and Outcome }\end{array}$ \\
\hline $\begin{array}{l}\text { Lessov- } \\
\text { Schlaggar } \\
\text { et al., } 2008\end{array}$ & Smoking & $\begin{array}{l}\text { Past week } \\
\text { smoking quantity }\end{array}$ & $13-24$ & 6 & $\begin{array}{l}50 \% \text { nonsmokers } \\
24 \% \text { experimenters } \\
8 \% \text { late increasers } \\
8 \% \text { early increasers } \\
5 \% \text { quitters } \\
5 \% \text { persistent }\end{array}$ & & $\begin{array}{l}\text { Lifetime nicotine } \\
\text { dependence at age } 29\end{array}$ & $\begin{array}{l}\text { Late increasers, early increasers, } \\
\text { quitters, and persistent smokers }> \\
\text { than experimenters }> \\
\text { nonsmokers }\end{array}$ \\
\hline Maggi, 2008 & Smoking & $\begin{array}{l}\text { Current } \\
\text { smoking } \\
\text { frequency }\end{array}$ & $10-21$ & 6 & $\begin{array}{l}48 \% \text { nonsmokers } \\
4 \% \text { late onset, daily } \\
17 \% \text { late onset, low } \\
6 \% \text { early onset, daily } \\
11 \% \text { early onset, } \\
\text { occasional } \\
14 \% \text { late onset, occasional }\end{array}$ & & NA & NA \\
\hline $\begin{array}{l}\text { Orlando et al., } \\
2004\end{array}$ & Smoking & $\begin{array}{l}\text { Current } \\
\text { smoking quantity/ } \\
\text { frequency }\end{array}$ & $13-23$ & 6 & $\begin{array}{l}10 \% \text { early increasers } \\
10 \% \text { late increasers } \\
28 \% \text { non-smokers } \\
40 \% \text { triers } \\
6 \% \text { decreasers } \\
6 \% \text { stable high }\end{array}$ & & $\begin{array}{l}\text { Past year mental \& } \\
\text { physical health, alcohol } \\
\text { \& drug problems at age } \\
23\end{array}$ & $\begin{array}{l}\text { Health: nonsmokers }>\text { triers }>\text { other } \\
\text { groups; MH: nonsmokers, triers } \\
\text { and decreasers }>\text { increaser } \\
\text { trajectories; alcohol or drug } \\
\text { problems: stable highs and both } \\
\text { increaser trajectories }> \\
\text { nonsmokers and triers }\end{array}$ \\
\hline $\begin{array}{l}\text { Brook et al., } \\
2008\end{array}$ & Smoking & $\begin{array}{l}\text { Smoking } \\
\text { quantity }\end{array}$ & $14-32$ & 5 & $\begin{array}{l}44 \% \text { nonsmokers } \\
10 \% \text { occasional } \\
20 \% \text { late start } \\
9 \% \text { quitters } \\
16 \% \text { heavy }\end{array}$ & & NA & NA \\
\hline $\begin{array}{l}\text { Riggs et al., } \\
2007\end{array}$ & Smoking & $\begin{array}{l}\text { Weekly } \\
\text { cigarette use }\end{array}$ & $12-24$ & 4 & $\begin{array}{l}47 \% \text { abstainers } \\
24 \% \text { low } \\
16 \% \text { late heavy } \\
12 \% \text { early heavy }\end{array}$ & & $\begin{array}{l}\text { Nicotine dependence at } \\
\text { age } 26,27 \text {, or } 28\end{array}$ & $\begin{array}{l}\text { Nicotine dependence: early heavy } \\
\text { smokers }>\text { late heavy }>\text { low }> \\
\text { abstainers }\end{array}$ \\
\hline $\begin{array}{l}\text { White et al., } \\
2002\end{array}$ & Smoking & $\begin{array}{l}\text { Past } 12 \text {-month } \\
\text { cigarette } \\
\text { frequency }\end{array}$ & $12-30$ & 3 & $\begin{array}{l}40 \% \text { nonsmokers } \\
19 \% \text { occasional } \\
41 \% \text { heavy }\end{array}$ & & NA & NA \\
\hline $\begin{array}{l}\text { Brown et al., } \\
\quad 2004\end{array}$ & Marijuana & $\begin{array}{l}\text { Past } 12 \text {-month } \\
\text { marijuana use } \\
\text { frequency }\end{array}$ & $12-20$ & 3 & $\begin{array}{l}\text { European American } \\
13 \% \text { early increase } \\
46 \% \text { late increase } \\
41 \% \text { abstainers } \\
\text { African American } \\
6 \% \text { early decrease } \\
24 \% \text { late increase } \\
70 \% \text { abstainers }\end{array}$ & & $\begin{array}{l}\text { Past } 12 \text {-month alcohol, } \\
\text { marijuana, drug use; } \\
\text { psychopathology at } \\
\text { age } 20\end{array}$ & $\begin{array}{l}\text { Overall negative outcomes: early }> \\
\text { late increasers }>\text { abstainers }\end{array}$ \\
\hline
\end{tabular}




$\begin{array}{ll}\text { Ellickson et al., } \quad \text { Marijuana } & \begin{array}{l}\text { Past 12-month and } \\ \text { past month } \\ \text { marijuana use } \\ \text { frequency }\end{array}\end{array}$

$\begin{array}{cc}\text { Windle \& } & \text { Marijuana } \\ \text { Wiesner, 2004 } & \begin{array}{c}\text { Past 6-month } \\ \text { marijuana use } \\ \text { frequency }\end{array}\end{array}$

Schulenberg et al., 2005

Marijuana $\quad \begin{aligned} & \text { Past 12-month and } \\ & \text { past 30-day } \\ & \text { marijuana use } \\ & \text { frequency }\end{aligned}$

Connell,

Dishion, \&

Deater-

Deckard, 2006

Wanner et al.,

2006

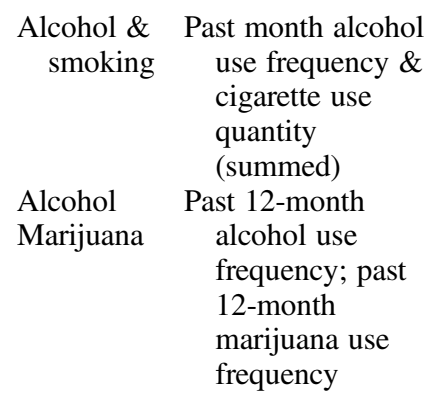

$\begin{array}{ccc}\begin{array}{c}\text { Flory } \\ \text { et al., 2004 }\end{array} & \begin{array}{l}\text { Alcohol } \\ \text { Marijuana }\end{array} & \begin{array}{c}\text { Past month alcohol } \\ \text { use frequency; } \\ \text { past 12-month } \\ \text { marijuana use } \\ \end{array} \\ & \text { frequency }\end{array}$

13-23 $5 \quad 45 \%$ abstainers

$10 \%$ stable light

$3 \%$ early high

$14 \%$ steady increase

$29 \%$ occasional light

$\begin{array}{ll}15-17 \quad 5 \quad & 81 \% \text { abstainers } \\ & 3 \% \text { decreasers } \\ & 9 \% \text { experimenters } \\ & 2 \% \text { high chronics } \\ & 4 \% \text { increasers }\end{array}$

.
18-24 $7 \quad 47 \%$ abstainers
$28 \%$ rare
$7 \%$ decreasing

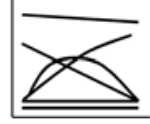

$5 \%$ increasing

$6 \%$ fling

$3 \%$ no pattern

$5 \%$ chronic

12-15 $5 \quad 7 \%$ decelerators

$26 \%$ low use

$52 \%$ no use

$6 \%$ early accelerators

$9 \%$ late accelerators

11-16 4 (Alc) Alcohol

$24 \%$ low consistent

$31 \%$ early onset

$45 \%$ late onset

Marijuana

3 (Mj) $\quad 74 \%$ low consistent $5 \%$ early onset $20 \%$ late onset

11-21 3 Alcohol (M/F)

$19 \% / 18 \%$ nonusers

$17 \% / 25 \%$ early onse $64 \% 157 \%$ late onset

Marijuana (M/F)

$39 \% / 46 \%$ nonusers

$6 \% / 12 \%$ early onset

$56 \% / 42 \%$ late onset
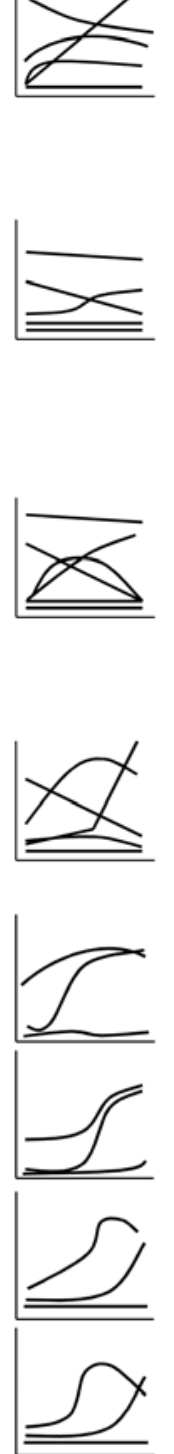

Health, mental health, life Health: abstainers $>$ light groups \& satisfaction, hard drug

use at age 29

Lifetime alcohol use

disorder, cannabis use

disorder, major

depression, and anxiety

at age 23

NA

NA

NA

NA

NA health: abstainers $>$ occasional

light \& increasers; life

satisfaction: abstainers $>$ all other groups; hard drug use: abstainers $<$ occasional light $<$ other groups

Alcohol use disorder: decreasers,

experimenters, \& increasers $>$ chronics > abstainers;

Cannabis use disorder: chronics $>$

increasers $>$ decreasers \&

experimenters $>$ abstainers;

Depression \& anxiety: no trajectory effects

NA

Alcohol use disorder marijuana use disorder, depression $\&$ anxiety at age 20-22
Alcohol use trajectories

Alcohol use disorder: early onset

$>$ late onset $>$ nonusers;

marijuana use disorder: early

onset $>$ late onset $>$ nonusers;

depression \& anxiety: no

trajectory effects

Marijuana use trajectories

Alcohol use disorder: early onset

$>$ late onset $>$ nonusers;

marijuana use disorder: early

onset \& late onset $>$ nonusers;

depression \& anxiety: no

trajectory effects 
Table 1 (cont.)

\begin{tabular}{|c|c|c|c|c|c|c|c|c|}
\hline Study & Substance & Trajectory Measure & $\begin{array}{l}\text { Traj. } \\
\text { Age } \\
\text { Range }\end{array}$ & $\begin{array}{l}\text { No of } \\
\text { Traj. }\end{array}$ & Prevalence of Trajectories & $\begin{array}{l}\text { Trajectory } \\
\text { Shapes }\end{array}$ & Outcomes & $\begin{array}{c}\text { Relationship Between Trajectory } \\
\text { and Outcome }\end{array}$ \\
\hline $\begin{array}{l}\text { Lynne- } \\
\text { Landsman, } \\
\text { Bradshaw, \& } \\
\text { Ialongo, 2010 }\end{array}$ & $\begin{array}{l}\text { Alcohol } \\
\text { Smoking } \\
\text { Marijuana }\end{array}$ & $\begin{array}{l}\text { Current use } \\
\text { frequency }\end{array}$ & $14-18$ & $\begin{array}{l}3(\mathrm{Alc}) \\
2(\mathrm{Sm}) \\
3(\mathrm{Mj})\end{array}$ & $\begin{array}{l}\text { Alcohol } \\
82 \% \text { none/low } \\
13 \% \text { moderate } \\
5 \% \text { heavy } \\
\text { Smoking } \\
82 \% \text { abstaining } \\
18 \% \text { increasing } \\
\text { Marijuana } \\
82 \% \text { abstaining } \\
11 \% \text { increasing } \\
7 \% \text { heavy }\end{array}$ & $\bar{\square}$ & $\begin{array}{l}\text { Alcohol use disorder, } \\
\text { marijuana use disorder, } \\
\text { illicit drug use, major } \\
\text { depression at age } 21\end{array}$ & $\begin{array}{l}\text { Alcohol use trajectories } \\
\text { Alcohol use disorder: no } \\
\text { trajectory effects } \\
\text { Marijuana use disorder: moderate } \\
>\text { low Illicit drug use: heavy \& } \\
\text { moderate }>\text { low Depression: no } \\
\text { trajectory effects } \\
\text { Smoking trajectories } \\
\text { Alcohol use disorder: increasing } \\
>\text { abstaining for abuse, but not } \\
\text { dependence; marijuana use } \\
\text { disorder: increasing }>\text { abstaining } \\
\text { for dependence, but not abuse; } \\
\text { illicit drug use: increasing }> \\
\text { abstaining depression: no } \\
\text { trajectory effects } \\
\text { Marijuana use trajectories } \\
\text { Alcohol use disorder: increasing } \\
\& \text { heavy }>\text { abstaining for abuse, } \\
\text { but not dependence; marijuana } \\
\text { use disorder: increasing \& heavy } \\
>\text { abstaining; Illicit drug use: } \\
\text { heavy \& moderate }>\text { abstaining } \\
\text { depression: abstaining }<\text { heavy }\end{array}$ \\
\hline $\begin{array}{l}\text { Chassin, Flora, } \\
\text { \& King, } 2004\end{array}$ & $\begin{array}{l}\text { Alcohol \& } \\
\text { drug }\end{array}$ & $\begin{array}{l}\text { Past 12-month } \\
\text { drinking quantity/ } \\
\text { frequency; past } \\
\text { 12-month illicit } \\
\text { drug use } \\
\text { frequency }\end{array}$ & $11-30$ & 4 & $\begin{array}{l}11 \% \text { Alc/drug abstainers } \\
24 \% \text { Alc light/drug rare } \\
45 \% \text { Alc mod/drug } \\
\text { experiment } \\
20 \% \text { Alc/drug heavy }\end{array}$ & Drug & $\begin{array}{l}\text { Alcohol or drug } \\
\text { dependence at age } \\
27-30\end{array}$ & $\begin{array}{l}\text { Alc/drug heavy }>\text { alc mod/drug } \\
\text { experiment }>\text { alc light/drug rare } \\
\& \text { alc/drug abstainers }\end{array}$ \\
\hline
\end{tabular}




\begin{tabular}{|c|c|c|c|c|c|c|c|c|}
\hline $\begin{array}{l}\text { Orlando et al., } \\
2005\end{array}$ & $\begin{array}{r}\text { Alcohol \& } \\
\text { smoking }\end{array}$ & $\begin{array}{l}\text { Past 12-month } \\
\text { drinking } \\
\text { frequency; past } \\
\text { 12-month } \\
\text { smoking } \\
\text { frequency }\end{array}$ & $13-23$ & 6 & $\begin{array}{l}5 \% \text { Alc/Sm nonusers } \\
6 \% \text { Alc maintain/Sm } \\
\text { quitters } \\
55 \% \text { Alc/Sm normative } \\
13 \% \text { Alc/Sm steady } \\
\text { increasers } \\
\text { 12\% Alc/Sm early } \\
\text { increasers } \\
9 \% \text { Alc/Sm early highs }\end{array}$ & Alcohol & $\begin{array}{l}\text { Health problems, life } \\
\text { dissatisfaction, alcohol } \\
\text { or drug use problem, } \\
\text { mental health problems } \\
\text { at age } 29\end{array}$ & $\begin{array}{l}\text { Health problems: nonusers \& } \\
\text { normative users }<\text { steady } \\
\text { increasers, early increasers, \& } \\
\text { early highs; quitters/maintainers } \\
\& \text { steady increasers }<\text { early highs; } \\
\text { life dissatisfaction: nonusers \& } \\
\text { normative users }<\text { steady } \\
\text { increasers, early increasers, \& } \\
\text { early highs, quitters/maintainers } \\
<\text { early highs; alcohol or drug use } \\
\text { problem: nonusers \& normative } \\
\text { users }<\text { quitters/maintainers \& } \\
\text { steady increasers }<\text { early } \\
\text { increasers }<\text { early highs; mental } \\
\text { health problems: no trajectory } \\
\text { effects }\end{array}$ \\
\hline $\begin{array}{l}\text { Jackson et al., } \\
2008\end{array}$ & $\begin{array}{l}\text { Alcohol } \\
\text { Smoking } \\
\text { Marijuana }\end{array}$ & $\begin{array}{l}\text { Past 2-week heavy } \\
\text { drinking } \\
\text { frequency; past } \\
\text { 30-day cigarette } \\
\text { quantity; past 30- } \\
\text { day marijuana use } \\
\text { frequency }\end{array}$ & $18-26$ & $\begin{array}{l}4 \text { (Alc) } \\
4(\mathrm{MJ}) \\
5(\mathrm{~S})\end{array}$ & $\begin{array}{l}\text { Heavy Drinking } \\
63 \% \text { low/no } \\
8 \% \text { late onset } \\
16 \% \text { dev. limited } \\
12 \% \text { chronic } \\
\text { Marijuana } \\
80 \% \text { low/no } \\
4 \% \text { late onset } \\
9 \% \text { dev. limited } \\
7 \% \text { chronic } \\
\text { Smoking } \\
69 \% \text { low/no } \\
6 \% \text { late onset } \\
6 \% \text { dev. limited } \\
12 \% \text { chronic } \\
8 \% \text { moderate }\end{array}$ & & NA & NA \\
\hline $\begin{array}{l}\text { Jackson, Sher, \& } \\
\text { Schulenberg, } \\
2005\end{array}$ & $\begin{array}{r}\text { Alcohol \& } \\
\text { smoking }\end{array}$ & $\begin{array}{l}\text { Past 2-week heavy } \\
\text { drinking } \\
\text { frequency; past } \\
\text { 30-day cigarette } \\
\text { quantity }\end{array}$ & $18-26$ & 7 & $\begin{array}{l}6 \% \text { chronic Alc/Sm } \\
14 \% \text { chronic Alc/low } \\
\text { Sm } \\
5 \% \text { mod. Alc/dev. } \\
\text { limited Sm } \\
56 \% \text { no Alc/Sm } \\
8 \% \text { low Alc/chronic Sm } \\
5 \% \bmod \text { Alc/late onset } \\
\text { Sm } \\
6 \% \bmod \text { Alc/mod Sm }\end{array}$ & & NA & NA \\
\hline
\end{tabular}

Note: Traj., Trajectory; inc., increase; dec., decrease; HS, high school; MS, middle school; M, male; F, female; Alc, alcohol; Mj, marijuana; Sm, smoking. All trajectories except those from Schulenberg et al., 1996, were calculated using growth mixture modeling or group-based trajectory modeling. Schulenberg et al. a priori categorizations were confirmed via cluster analysis. 
a range of use trajectories, from three to six (Brown, Flory, Lynam, Leukefeld, \& Clayton, 2004; Ellickson, Martino, \& Collins, 2004; Schulenberg et al., 2005; Windle \& Wiesner, 2004). All include a no/low use trajectory and early onset/ chronic trajectory, similar to those of other substances.

Only two studies have related marijuana use trajectories to young adult outcomes. One found that individuals who fell into any of the groups that used marijuana more than occasionally had higher likelihood of hard drug use at age 29; occasional users had a higher likelihood of hard drug use than did nonusers (Ellickson et al., 2004). The other found that high-level users and gradual increasers were at greater risk of a marijuana use disorder in adulthood than were others (Windle \& Wiesner, 2004).

Overall, marijuana use trajectories appear quite similar to those for both alcohol and tobacco use and appear to be associated with other drug use disorders in young adulthood.

\section{Multiple trajectories}

Several studies have investigated co-occurrence of multiple substance use trajectories. As shown in Table 1, these studies have demonstrated significant overlap between various substance use trajectories. Not only are adolescents who use one substance more likely to use another, but in studies that found similar trajectories for each substance, adolescents who belonged to a specific trajectory for one substance were more likely to belong to that same trajectory for another substance (e.g., Flory, Lynam, Milich, Leukefeld, \& Clayton, 2004; Jackson, Sher, \& Schulenberg, 2008).

In terms of outcomes, researchers (Flory et al., 2004; Orlando, Tucker, Ellickson, \& Klein, 2005; Wanner, Vitaro, Ladouceur, Brendgen, \& Tremblay, 2006) have found that adolescents with early onset of these behaviors were at greater risk for poor substance-related outcomes in adulthood. Late onset of either alcohol use or marijuana use was not linked strongly to these poor outcomes, but late onset and escalation of more than one behavior did predict risk for later problems. In Flory et al.'s (2004) study, early-onset alcohol users had a greater likelihood of both alcohol and marijuana dependence in young adulthood than did late-onset users, who had higher likelihoods than did nonusers. For marijuana, this same pattern emerged for alcohol dependence, but both marijuana-onset groups were indistinguishable from each other in terms of risk for marijuana dependence. In Orlando et al.'s (2005) study of alcohol and smoking trajectories, members of the high-use and early-increasing trajectories were more likely to experience alcohol and drug use problems in young adulthood than were the gradual increasers and the decreasing smokers, who in turn had greater likelihood of these problems than did the nonusers or normative users.

\section{Limits of past work}

Past trajectory work has provided valuable information about individual differences in substance use patterns from early adolescence to adulthood. In particular, the work has clearly identified a pathway to substance use problems that involves early initiation and chronic use, as well as the use of multiple substances. This trajectory likely maps onto frameworks that specify a group of individuals with underlying genetic and/ or emotion and impulse regulation vulnerabilities. However, multiple substance trajectory work has been limited to a handful of studies, and even fewer have investigated the outcomes of those multiple trajectories. In particular, while a base of research has clearly discriminated heavy chronic users from no/ low users of various substances in terms of their outcomes, much less is known about the developmental outcomes of other patterns and trajectories of substance use that emerge during adolescence. These are the trajectories that appear to be more amenable to environmental influences and potentially to interventions, and thus are an important target of study.

Our study adds to the existing literature by examining multiple trajectories, measuring these trajectories from middle school through young adulthood, and examining how these trajectories relate to substance use outcomes. To our knowledge, no study has examined alcohol, marijuana, and tobacco use trajectories conjointly across more than 10 years. Those that have examined multiple trajectories across similar age ranges (e.g., Flory et al., 2004; Orlando et al., 2005) were conducted 10 years prior to our study. In addition, our study focuses on trajectory shape, as well as onset, and investigates how different trajectory shapes that share similar age of onset differentiate outcomes.

\section{Current Study}

The current study analyzed longitudinal substance use data from a large, diverse sample of adolescents from age 12 to age 24 to identify trajectories of substance use and how those trajectories relate to young adult substance use outcomes. The primary aims of the study were to (a) identify trajectory groups and their prevalence for alcohol use, marijuana use, and tobacco use, and examine whether inclusion of data beyond high school establishes trajectories that differ from those identified in previous research; (b) investigate whether specific trajectories of alcohol, marijuana, and tobacco use tend to co-occur; and (c) determine whether aspects of trajectories beyond age of onset suggest increased risk for young adult substance use problems. We hypothesized that our study would identify trajectories similar to those found in past research, but that additional trajectories would emerge based on inclusion of data gathered beyond high school. We also expected significant co-occurrence between trajectories for different substances. We did not generate specific hypotheses about how the shapes of trajectories might relate to outcomes, because of the exploratory nature of these analyses.

\section{Methods}

\section{Participants}

The participants were 998 students enrolled in a longitudinal intervention study that began when they were in Grade 6 and 
continues to collect data about the participants, now in their 20s. The study follows two cohorts of adolescents separated by 2 years and initially spread across three schools in various neighborhoods of a medium-sized Northwest city. Half of the classrooms within these schools received a classwide intervention program. All students from Grade 6 classrooms in three schools were recruited for the study, which began in 1996. The recruitment rate was $95 \%$ for Cohort 1 and $83 \%$ for Cohort 2 . The study has retained approximately $80 \%$ of the original two cohorts from Grade 6 to 2 to 3 years beyond high school. The sample is $42 \%$ European American, 29\% African American, 7\% Hispanic, 6\% Asian American, 2\% Native American, and $14 \%$ multiracial. Forty-seven percent of the sample is female. The current study analyzed data from nine survey waves conducted in Grades 6, 7, 8, 9, 11, and 12, as well as 1 year, 4 years, and 5 years post-high school. Participants were 1112 years old at the beginning of the study and 23-24 years old at the last survey wave; see Dishion and Kavanagh (2000) for more information about the sample and design of the study. For the current analyses, we excluded the $11 \%$ of participants who had missing data at more than three waves. These excluded participants did not differ significantly (i.e., $p<.05)$ from the rest of the sample on any baseline variables (i.e., ethnicity, college attendance, intervention status, alcohol use, tobacco use, or marijuana use) except gender. Excluded participants were more likely to be male $(68 \%)$ than were participants in the final sample $(32 \%), \chi^{2}(1, N=998)=10.8, p<$ .01 . The final sample for our study included 890 participants.

\section{Procedures}

From Grade 6 through Grade 9, participants completed questionnaires one time each year in their classroom. In Grades 11 and 12 and at ages 19-20, 22-23, and 23-24, participants completed questionnaire packets that were mailed to them. The questionnaires included a variety of measures, including questions about demographics, mental health, substance use, family relations, and peer relations.

Family intervention. In middle school, half of the sample was randomized to a Family Check-Up (FCU). The FCU is a three-session intervention that consists of an initial interview, an assessment session, and a feedback session by a trained parent consultant. Following the FCU, some families are provided with follow-up services that focus on supporting skillful family management practices. The intervention is described in considerable detail in three books (Dishion \& Kavanagh, 2003; Dishion \& Stormshak, 2007; Dishion, Stormshak, \& Kavanagh, 2011). For the current study, we included intervention status as a predictor of trajectory membership.

\section{Materials}

At every time point, participants answered demographic questions and a series of questions about their substance use. The study also obtained juvenile and adult arrest data about all participants, including information about substance-related arrests for alcohol (e.g., driving under the influence) and marijuana (e.g., possession).

Substance use questions. The Community Action for Successful Youth survey (Metzler, Ary, \& Biglan, 2002), administered at each wave in this study, includes a series of questions about alcohol, marijuana, and cigarette use in the past month. Specifically, at each data collection wave, participants answered the following questions: "How many cigarettes have you smoked, even a puff, in the last month?" "How many drinks of alcohol have you had in the last month?" and "How many times have you smoked marijuana in the last month?" Response options for cigarettes included integers between 0 and 9, inclusive: $10=1 / 2$ pack, $11=1$ pack, $12=2$ packs $\ldots .20=10$ packs, $21=11-20$ packs, $22=21-30$ packs, and $23=31$ or more packs. For alcohol and marijuana, response options included integers between 0 and 10, inclusive: $11=11-20,12=21-40$, and $13=41$ or more. The survey also includes a question about stimulant use; however, very few participants reported any stimulant use at all across the study, so these data were not modeled.

At the last two data collection waves, 4 and 5 years posthigh school (ages 22-23 and 23-24), participants also answered questions about frequency of substance use and about substance use problems. Specifically, participants indicated the frequency of their use of cigarettes, alcohol, and marijuana on an 8-point scale ranging from 0 (never) to 7 (2-3 times a day or more) for each substance. Participants also indicated whether they had tried unsuccessfully to stop using each substance, and for alcohol and for marijuana, whether they had trouble getting high and the extent to which they had experienced substance-related problems at school and/ or work. For alcohol, participants also indicated whether they had ever thrown up from drinking, whether they had ever passed out from drinking, whether they had ever lost or broken things when drinking, and how many times they had consumed five or more drinks in a row. To create composite "problematic use" variables for alcohol, marijuana, and tobacco at this age, we dichotomized the continuous variables at the median to indicate either "low" (coded 0) or "high" (coded 1) levels of use. Then, for each substance, we summed these variables. For alcohol and marijuana, we also included counts of alcohol-related and marijuana-related arrests, respectively, in the sum.

\section{Analyses}

Data were analyzed using a group-based trajectory modeling approach. We used the SAS-based procedure, Proc TRAJ, to create developmental trajectories from the alcohol, marijuana, and cigarette use data in the sample using a zero-inflated Poisson model. We tested two- to eight-group zero-inflated Poisson models and used the Bayesian information criterion, as well as examination of the trajectories, to deter- 
mine the best-fitting models. We selected the best-fitting model that maintained unique trajectories.

Model diagnostics. Nagin (2005) presents several diagnostics that can be used to assess the adequacy of a model. First among these is the average posterior probability, which is calculated for each trajectory group $j\left(\mathrm{AvePP}_{j}\right)$. In an ideal situation, each group has an $\mathrm{AvePP}_{j}=1$, which would indicate that each individual belongs in a given group with absolute certainty. However, such certainty rarely exists, and as the certainty declines, the $\mathrm{AvePP}_{j}$ also declines. Nagin's (2005) criterion is an $\mathrm{AvePP}_{j}$ of at least 0.7 for all groups. The second diagnostic presented in Nagin (2005) is the odds of correct classification (OCC), which is calculated for each group $j$ $\left(\mathrm{OCC}_{j}\right)$. If the model has no predictive power, then $\mathrm{OCC}_{j}$ equals 1 . As the model becomes more predictive, $\mathrm{OCC}_{j}$ increases. Nagin's (2005) criterion is an $\mathrm{OCC}_{j}$ of at least 5.0 for all groups. The third diagnostic compares the probability of group assignment $\left(\mathrm{Prob}_{j}\right)$, which is calculated for each group $j$, with the actual proportion of individuals assigned to each group using the "maximum posterior probability classification rule" $\left(\operatorname{Prop}_{j}\right)$. If individuals were assigned to each group with absolute certainty (i.e., AvePP ${ }_{j}=1$ for all groups $j$ ), then the probability would equal the proportion assigned using the classification rule. As the assignment error increases, then the gap between the two figures will grow. Nagin (2005) provides no criterion but does point to a difference of $50 \%$ in the values as being uncomfortably large. We use and report all of these statistics as model diagnostics.

Predictors and outcomes. Predictors of trajectory membership were not the focus of this investigation. However, because past research has suggested that substance use patterns vary by gender and race, as well as by college status, we included them in our analyses. To investigate demographic predictors (i.e., race, gender, and college status) of trajectory membership, as well as control for intervention effects, we used "risk factor analysis" within Proc TRAJ. When examining predictors of group membership, group-based modeling provides the log odds of the impact of each predictor on the likelihood of membership in each trajectory group relative to a baseline or comparison group (see Nagin, 2005). The results from this analysis can be considered a set of binary logistic regression models that predicts group membership in the designated comparison group versus each of the other groups in the model.

To investigate age $22-23$ problematic substance use outcomes associated with trajectory membership, we used "outcome analysis" within Proc TRAJ. In an outcome analysis, posterior probabilities of trajectory group membership are used as weights for each individual's outcome value, and the resulting values are summed for each trajectory group to arrive at the group's average outcome value. The posterior probabilities represent the probability that each member of the sample belongs to each trajectory group in the model; together, the posterior probabilities for each individual sum to
1.0. Once each group's weighted outcome value is calculated, the values can be compared in a pairwise fashion using a Wald test.

Dual trajectory analysis. To investigate overlap between trajectories, we used dual trajectory analysis. Dual trajectory analysis (Jones \& Nagin, 2007; Nagin, 2005) is based upon the posterior probabilities of group membership. When two sets of trajectories are brought together (e.g., trajectories of alcohol and of marijuana use), each individual will have two sets of posterior probabilities representing membership in each of the sets of trajectories. Using these probabilities, the joint likelihood of membership in each possible combination of trajectories can be calculated. In our study, we examined the membership of each trajectory group for each substance in terms of the other substance trajectories. For example, the members of each alcohol use trajectory group were apportioned in terms of their membership in trajectories of tobacco and marijuana. In addition, we examined the most common trajectory overlap patterns and the overlap between high-risk trajectories.

Relationship between trajectory overlap and outcomes. To investigate the relationship between trajectory overlap and outcome, we assigned participants to their most likely trajectories for alcohol, marijuana, and tobacco use. For each substance, we established high risk, moderate risk, some risk, and no/low risk trajectory categories based on post hoc tests of the differences between trajectory groups on problematic substance use outcomes. This strategy resulted in each participant having a score between 1 (no/low risk trajectory group) and 4 (high risk trajectory group) for each substance use trajectory (i.e., alcohol, marijuana, and tobacco use). We then conducted hierarchical regressions with the following steps for each problematic substance use outcome: Step 1: entered trajectory risk group corresponding to the outcome (e.g., alcohol trajectory risk group if outcome was problematic alcohol use); Step 2: entered other two trajectory risk groups; Step 3: entered two-way interactions between trajectory risk groups; and Step 4: entered three-way interaction between trajectory risk groups.

\section{Results}

\section{Alcohol}

Alcohol use trajectories. The mathematically best-fitting trajectory model included eight trajectories. Model diagnostics suggested that we had a well-fitting model (see Table 2). Examination of the trajectories indicated that each reflected a unique pattern of alcohol use, so we chose to retain the eight-trajectory model. These eight trajectories, plotted in Figure 1, included abstainers (14.2\% of the sample), earlyonset low users $(5.4 \%)$, young adult-onset moderate increasers $(8.7 \%)$, young adult-onset moderate decreasers $(8.4 \%)$, young adult-onset steep increasers (26.8\%), post-high 
Table 2. Diagnostics of model adequacy

\begin{tabular}{|c|c|c|c|c|c|}
\hline Trajectory & $\mathrm{AvePP}_{j}$ & $\mathrm{OCC}_{j}$ & $\operatorname{Prob}_{j}$ & Prop $_{j}$ & |\% Dif. $\mid$ \\
\hline \multicolumn{6}{|c|}{ Alcohol Model } \\
\hline 1. Abstainers & $.824^{a}$ & $28.3^{a}$ & .142 & .153 & $7.7^{a}$ \\
\hline 2. EO low users & $.861^{a}$ & $108.5^{a}$ & .054 & .041 & $24.1^{a}$ \\
\hline 3. YA moderate $\uparrow$ & $.790^{a}$ & $39.5^{a}$ & .087 & .076 & $12.6^{a}$ \\
\hline 4. YA moderate $\downarrow$ & $.740^{a}$ & $31.0^{a}$ & .084 & .078 & $7.1^{a}$ \\
\hline 5. YA steep $\uparrow$ & $.708^{a}$ & $6.6^{a}$ & .268 & .322 & $20.1^{a}$ \\
\hline 6. pHS steep $\uparrow$ & $.798^{a}$ & $17.8^{a}$ & .182 & .169 & $7.1^{a}$ \\
\hline 7. HS steep $\uparrow$ & $.860^{a}$ & $45.5^{a}$ & .119 & .106 & $10.9^{a}$ \\
\hline 8. EO moderate $\uparrow$ & $.900^{a}$ & $136.2^{a}$ & .062 & .054 & $12.9^{a}$ \\
\hline \multicolumn{6}{|c|}{ Marijuana Model } \\
\hline 1. Abstainers & $.888^{a}$ & $7.2^{a}$ & .525 & .580 & $10.5^{a}$ \\
\hline 2. EO low $\downarrow$ & $.828^{a}$ & $84.3^{a}$ & .054 & .046 & $14.8^{a}$ \\
\hline 3. YA low $\downarrow$ & $.803^{a}$ & $39.3^{a}$ & .094 & .081 & $13.8^{a}$ \\
\hline 4. YA steep $\uparrow$ & $.772^{a}$ & $35.1^{a}$ & .088 & .086 & $2.3^{a}$ \\
\hline 5. pHS high $\downarrow$ & $.758^{a}$ & $45.1^{a}$ & .065 & .053 & $18.5^{a}$ \\
\hline 6. HS steep $\uparrow$ & $.902^{a}$ & $78.5^{a}$ & .105 & .093 & $11.4^{a}$ \\
\hline 7. EO high $\downarrow$ & $.862^{a}$ & $84.3^{a}$ & .069 & .060 & $13.0^{a}$ \\
\hline \multicolumn{6}{|c|}{ Tobacco Model } \\
\hline 1. Abstainers & $.815^{a}$ & $6.9^{a}$ & .388 & .470 & $21.1^{a}$ \\
\hline 2. Very low users & $.823^{a}$ & $41.9^{a}$ & .100 & .063 & $37.0^{a}$ \\
\hline 3. pHS low $\downarrow$ & $.805^{a}$ & $38.0^{a}$ & .098 & .084 & $14.3^{a}$ \\
\hline 4. YA moderate $\uparrow$ & $.848^{a}$ & $42.9^{a}$ & .115 & .093 & $19.1^{a}$ \\
\hline 5. pHS steep $\uparrow$ & $.868^{a}$ & $28.2^{a}$ & .189 & .182 & $3.7^{a}$ \\
\hline 6. EO steep $\uparrow$ & $.931^{a}$ & $108.1^{a}$ & .111 & .107 & $3.6^{a}$ \\
\hline
\end{tabular}

Note: Ave PP, Average posterior probability; OCC, odds of correct classification; EO, early onset; YA, young adult onset; HS, high school onset; pHS, post-high school onset; $\uparrow$, increasers; $\downarrow$, decreasers.

${ }^{a}$ Exceeds criteria presented in Nagin (2005) as evidence for a well-fitting model.

school-onset steep increasers (18.2\%), high school-onset steep increasers (11.9\%), and early-onset moderate increasers $(6.2 \%)$.

Characteristics of alcohol use trajectory groups. Membership in alcohol use trajectories varied by gender, race, and college status (see Table 3). Being male predicted membership in the high school and post-high school-onset trajectories compared to the abstainer trajectory. Being European American predicted membership in the early-increasing, high school, and post-high school-onset trajectories compared to the abstainer trajectory. Finally, not attending college within 2 years of graduating high school was associated with membership in both early-onset trajectories. Neither gender, race, nor college status predicted the young adult-onset trajectories, compared to the abstainer trajectory. Random assignment to the FCU was not associated with membership in any of the eight alcohol use trajectories.

Alcohol use trajectory groups and age 22-23 problematic alcohol use. Table 4 shows age 22-23 problematic alcohol use outcomes for each alcohol use trajectory. Members of the abstainer and young adult-onset moderate increaser trajectories had low levels of problematic alcohol use disorders in young adulthood. Though the young adult declining trajectory members had relatively low levels of problematic use, the young adult steep increasing trajectory had higher problematic use outcomes than did the other young adult trajectories and the early-onset, low-use trajectory. Of the remaining trajectories, the high school-onset group had the highest levels of problematic use at age 22-23, followed by the post-high school-onset group and the early-onset increasers.

\section{Marijuana}

Marijuana use trajectories. The best-fitting trajectory model included seven trajectories. Model diagnostics suggested that we had a well-fitting model (see Table 2). Examination of the trajectories indicated that each reflected a unique pattern of marijuana use, so we chose to retain the seven-trajectory model. These seven trajectories, plotted in Figure 2, included abstainers (52.5\% of the sample), early-onset low/decreasing users (5.4\%), young adult-onset low/decreasing users (9.4\%), young adult-onset steep increasers $(8.8 \%)$, post-high schoolonset high decreasers (6.5\%), high school-onset steep increasers $(10.5 \%)$, and early-onset high decreasers $(6.2 \%)$.

Characteristics of marijuana use trajectory groups. Membership in marijuana use trajectories varied by gender, race, college status, and intervention status (see Table 3). Being male predicted membership in the high school-onset trajectory, and being female predicted membership in the early-onset low/decreasing use trajectory compared to the abstaining group. Being European American predicted membership in both young adult trajectories and the high school-onset trajectory compared to the abstaining group. Attending college within 2 years of graduating high school predicted membership in the young adult-onset low/decreasing trajectory, and not attending college within 2 years of graduating high school was associated with membership in the two earlyonset trajectories. Neither gender, race, college status, nor intervention status predicted the post-high school-onset trajectory. Finally, participants who did not receive the intervention were more likely to belong to the high school-onset trajectory than to the abstainer trajectory.

Marijuana use trajectory groups and age 22-23 problematic marijuana use. Table 4 shows age 22-23 problematic marijuana use outcomes for each marijuana use trajectory. Abstainers and early-onset, low-level users had relatively low levels of problematic marijuana use in young adulthood. The young adult-onset declining users and the early-onset high-level but declining users had the next lowest rates of problematic use, followed by the post-high school-onset declining trajectory. Both steep increasers, those with young adult-onset and those with high school-onset, had the highest rates of problematic use in their early 20 s. 


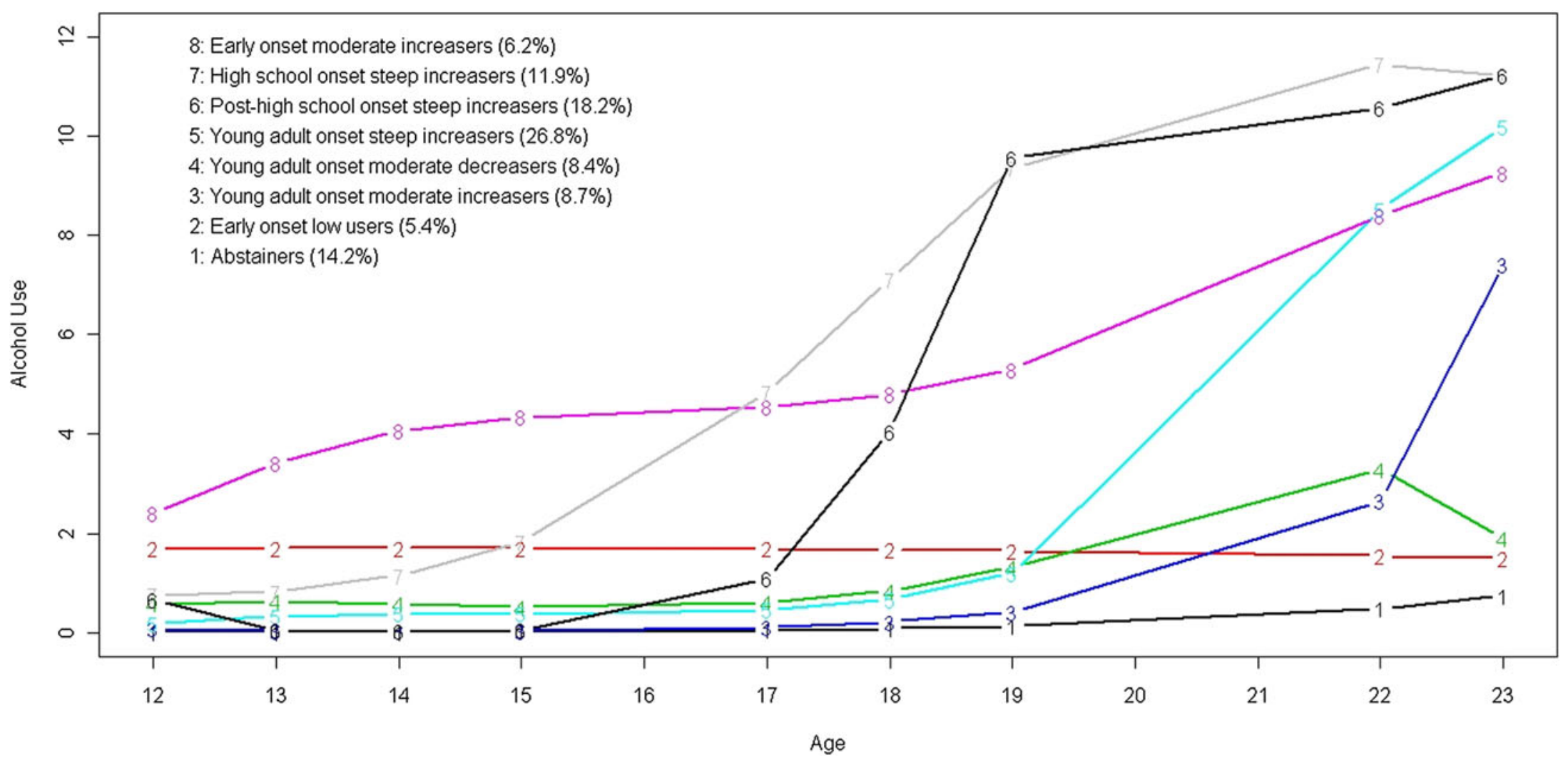

Figure 1. (Color online) Alcohol use trajectories. 
Table 3. Predictors of trajectory membership (log odds estimate [SE])

\begin{tabular}{|c|c|c|c|c|}
\hline Trajectory & Gender (Female) & Race (Eur. Amer.) & College Attendance & Intervention \\
\hline \multicolumn{5}{|l|}{ Alcohol } \\
\hline 1. Abstainers & - & - & - & - \\
\hline 2. EO low users & $-0.10(0.48)$ & $0.63(0.54)$ & $-1.32 *(0.67)$ & $0.37(0.49)$ \\
\hline 3. YA moderate $\uparrow$ & $0.09(0.37)$ & $0.28(0.43)$ & $-0.49(0.45)$ & $-0.63(0.38)$ \\
\hline 4. YA moderate $\downarrow$ & $0.40(0.41)$ & $0.78(0.43)$ & $-5.88(13.75)$ & $0.14(0.39)$ \\
\hline 5. YA steep $\uparrow$ & $-0.41(0.29)$ & $0.59(0.32)$ & $-0.21(0.32)$ & $-0.31(0.38)$ \\
\hline 6. pHS steep $\uparrow$ & $-1.17 * * *(0.32)$ & $1.38 * * *(0.35)$ & $0.02(0.34)$ & $-0.17(0.32)$ \\
\hline 7. HS steep $\uparrow$ & $-0.72 *(0.35)$ & $2.21 * * *(0.39)$ & $-0.15(0.39)$ & $-0.23(0.35)$ \\
\hline 8. EO moderate $\uparrow$ & $0.04(0.41)$ & $1.75 * * *(0.45)$ & $-1.63 * *(0.55)$ & $-0.05(0.42)$ \\
\hline \multicolumn{5}{|l|}{ Marijuana } \\
\hline 1. Abstainers & - & - & - & - \\
\hline 2. EO low $\downarrow$ & $1.00 *(0.45)$ & $0.32(0.40)$ & $-1.57 *(0.61)$ & $0.51(0.39)$ \\
\hline 3. YA low $\downarrow$ & $-0.31(0.34)$ & $1.39 * * *(0.37)$ & $1.25 * * *(0.34)$ & $-0.10(0.33)$ \\
\hline 4. YA steep $\uparrow$ & $-0.58(0.30)$ & $0.77 *(0.30)$ & $-0.64(0.38)$ & $0.17(0.30)$ \\
\hline 5. pHS high $\downarrow$ & $-0.51(0.38)$ & $-0.45(0.48)$ & $-1.90(1.24)$ & $0.13(0.38)$ \\
\hline 6. HS steep $\uparrow$ & $-1.52 * * *(0.33)$ & $0.75 * *(0.28)$ & $0.14(0.31)$ & $-0.72 *(0.29)$ \\
\hline 7. EO high $\downarrow$ & $0.33(0.37)$ & $-0.07(0.39)$ & $-2.92 * *(1.04)$ & $-0.69(0.37)$ \\
\hline \multicolumn{5}{|l|}{ Tobacco } \\
\hline 1. Abstainers & - & - & - & - \\
\hline 2. Very low users & $0.35(0.39)$ & $0.79 *(0.38)$ & $-0.24(0.40)$ & $-0.40(0.37)$ \\
\hline 3. pHS low $\downarrow$ & $-0.28(0.33)$ & $0.77 *(0.34)$ & $-0.88 *(0.44)$ & $0.37(0.33)$ \\
\hline 4. YA moderate $\uparrow$ & $-0.62 *(0.29)$ & $0.22(0.31)$ & $-0.60(0.33)$ & $-0.05(0.29)$ \\
\hline 5. pHS steep $\uparrow$ & $-0.51 *(0.23)$ & $0.67 * *(0.24)$ & $-1.68 * * *(0.34)$ & $0.03(0.23)$ \\
\hline 6. EO steep $\uparrow$ & $0.33(0.24)$ & $0.98 * * *(0.29)$ & $-2.62 * * *(0.54)$ & $-0.49(0.27)$ \\
\hline
\end{tabular}

Note: Trajectory 1 is the comparison group. EO, Early onset; YA, young adult onset; HS, high school onset; pHS, posthigh school onset; $\uparrow$, increasers; $\downarrow$, decreasers. $* p<.05 . * * p<.01 . * * * p<.001$.

\section{Tobacco}

Cigarette use trajectories. The best-fitting trajectory model included six trajectories. Model diagnostics suggested that we had a well-fitting model (see Table 2). Examination of the trajectories indicated that each reflected a unique pattern of cigarette use, so we chose to retain the six-trajectory model. These six trajectories, plotted in Figure 3, included abstainers $(38.8 \%$ of the sample), very low users $(10.0 \%)$, post-high school-onset low/moderate decreasing users $(9.8 \%)$, young adult-onset moderate increasers $(11.5 \%)$, post-high school-onset steep increasers $(18.9 \%)$, and early-onset steep increasers $(11.1 \%)$.

Characteristics of tobacco use trajectory groups. Membership in tobacco use trajectories varied by gender, race, and college status (see Table 3 ). Being male predicted membership in the post-high school-onset steep increasing trajectory and the young adult trajectory compared to the abstainer trajectory. Being European American predicted membership in the post-high school-onset trajectories, the early-onset trajectory, and the low-user trajectory compared to the abstainer trajectory. Finally, not attending college within 2 years of graduating high school was associated with membership in the two steep increasing trajectories: early onset and posthigh school, as well as the post-high school low decreasing trajectory. Intervention status was not associated with membership in any of the trajectories.
Table 4. Trajectory membership and substancerelated outcomes (mean [95\% confidence interval])

\begin{tabular}{lc}
\hline \hline \multicolumn{1}{c}{ Trajectory } & Age $22-23$ Problematic Use $^{a}$ \\
& $M(95 \%$ CI $)$ \\
\hline Alcohol & \\
1. Abstainers & $0.54(0.39,0.75)$ \\
2. EO low users & $2.46(2.02,3.01)$ \\
3. YA moderate $\uparrow$ & $1.04(0.77,1.41)$ \\
4. YA moderate $\downarrow$ & $2.98(2.49,3.57)$ \\
5. YA steep $\uparrow$ & $4.19(3.84,4.57)$ \\
6. pHS steep $\uparrow$ & $6.55(6.05,7.09)$ \\
7. HS steep $\uparrow$ & $7.08(6.49,7.73)$ \\
8. EO moderate $\uparrow$ & $5.13(4.46,5.90)$ \\
Marijuana & \\
1. Abstainers & $0.17(0.13,0.23)$ \\
2. EO low $\downarrow$ & $1.10(0.78,1.56)$ \\
3. YA low $\downarrow$ & $1.80(1.48,2.18)$ \\
4. YA steep $\uparrow$ & $3.28(2.72,3.96)$ \\
5. pHS high $\downarrow$ & $2.46(1.90,3.19)$ \\
6. HS steep $\uparrow$ & $4.67(4.17,5.24)$ \\
7. EO high $\downarrow$ & $2.11(1.64,2.71)$ \\
Tobacco & \\
1. Abstainers & \\
2. Very low users & $0.03(0.01,0.06)$ \\
3. pHS low $\downarrow$ & $0.92(0.68,1.24)$ \\
4. YA moderate $\uparrow$ & $1.17(0.91,1.52)$ \\
5. pHS steep $\uparrow$ & $2.09(1.76,2.49)$ \\
6. EO steep $\uparrow$ & $2.82(2.53,3.15)$ \\
\hline \hline
\end{tabular}

Note: EO, Early onset; YA, young adult onset; HS, high school onset; pHS, post-high school onset; $\uparrow$, increasers; $\downarrow$, decreasers. ${ }^{a}$ For each substance, the problematic use outcome is specific to that substance. 


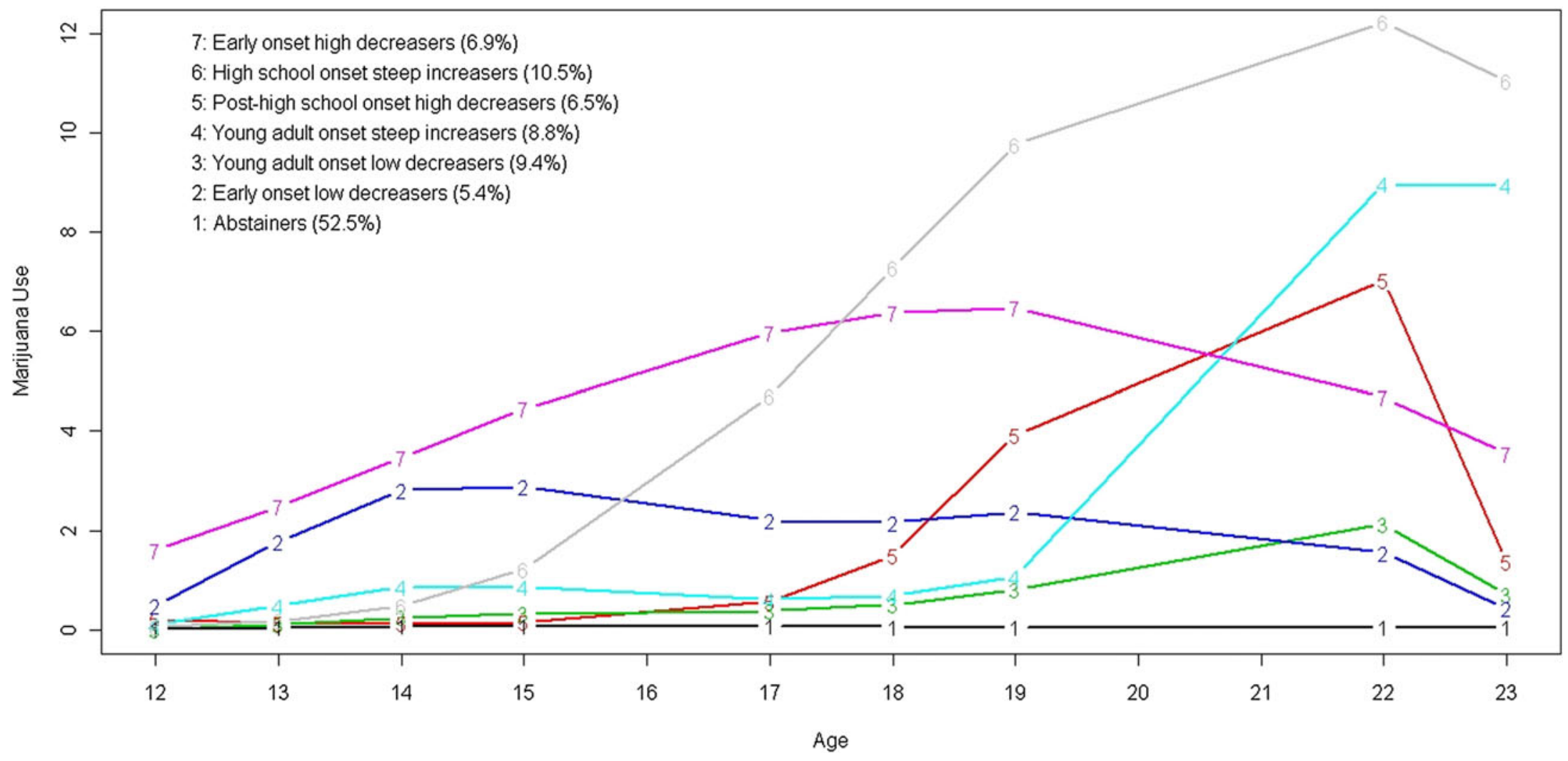

Figure 2. (Color online) Marijuana use trajectories. 
Tobacco use trajectory groups and age 22-23 problematic tobacco use. Table 4 shows problematic tobacco use outcomes at age 22-23 for each tobacco use trajectory. Abstainers and low users had relatively low levels of problematic tobacco use in their early 20s. The post-high school-onset declining trajectory members had the next lowest level of problematic tobacco use, followed by the young adult trajectory members. The post-high school-onset steep increasers and early-onset steep increasers had equivalently high levels of problematic use at age 22-23.

\section{Overlap between trajectories}

Twelve percent of the sample belonged to the nonuser trajectories for all three substances. Slightly more than $1 \%$ belonged to the early-onset, high-use trajectories for all three substances. We used dual trajectory analysis to examine the overlap between trajectories for different substances. Tables 5-7 display the overlap between trajectories.

Alcohol trajectory and marijuana trajectory membership. For alcohol and marijuana, $14.2 \%$ of the sample qualified as nonusers of both substances throughout the study. Almost all the members of the abstainer trajectory for alcohol (98.0\%) also belonged to the abstainer trajectory for marijuana use. The converse was not true; only $33.4 \%$ of marijuana abstainers also belonged to the alcohol abstainer trajectory. Almost all individuals who used marijuana used alcohol at some level through adolescence and young adulthood. However, many alcohol users did not use marijuana. Nonusers of marijuana who used alcohol were most likely to be members of the young adult-onset alcohol use trajectories, specifically the moderate- and high-use ones. Early-onset marijuana users were likely to be early-onset, high-use alcohol users but were also likely to belong to the young adultonset, moderate-decreasing alcohol trajectory. Early-onset, high-use alcohol trajectory members were also most likely to belong to the early-onset, high-use marijuana use trajectory. Almost half of the individuals who belonged to the high school steep-increase marijuana trajectory also belonged to that trajectory for alcohol, and a quarter of those individuals belonged to the post-high school, steep-increase alcohol trajectory.

Alcohol trajectory and tobacco trajectory membership. For alcohol and tobacco, $12.4 \%$ of the sample qualified as nonusers of both substances throughout the study. A large majority of the members of the abstainer trajectory for alcohol use $(90.2 \%)$ also belonged to the abstainer trajectory for tobacco use. Again, the converse was not true; only $35.7 \%$ of tobacco abstainers also belonged to the alcohol abstainer trajectory. Almost all individuals who used tobacco used alcohol at some level throughout the study, but the converse was not true. Nonusers of tobacco who used alcohol were most likely to be members of the young adult-onset, high-use alcohol use trajectory. Early-onset tobacco users were likely to be early- onset, high-use alcohol users but were also likely to belong to the high school-onset alcohol trajectory. Early-onset, high-use alcohol trajectory members were also most likely to belong to the early-onset, high-use tobacco use trajectory. None of the individuals who belonged to the early-onset and high school-onset alcohol use trajectories belonged to the abstainer tobacco use trajectory; all used tobacco to some extent.

Tobacco trajectory and marijuana trajectory membership. For tobacco and marijuana, $37.6 \%$ of the sample qualified as nonusers of both substances throughout the study. The majority of the members of the abstainer trajectory for marijuana use $(65.8 \%)$ also belonged to the abstainer trajectory for tobacco use. This was also the case for tobacco abstainers: $84.9 \%$ also belonged to the marijuana abstainer trajectory. Unlike the relationship between alcohol and marijuana, using either marijuana or tobacco was not strongly associated with using the other substance. However, young adult onset of the two substances was related. Almost $30 \%$ (29.5\%) of young adult-onset tobacco users were also young adult-onset marijuana users, also showing a pattern of steep increase in use during this period.

Trajectory overlap and outcomes. When categorized by trajectory risk level, as described in the Methods section, $23.5 \%$ of participants qualified as no/low risk for all three trajectories, and 3.9\% qualified as high risk for all three trajectories. As described in the Methods section, we ran three hierarchical regression analyses, one for each problematic substance use outcome. The results of these analyses are displayed in Table 8.

For problematic alcohol use, alcohol trajectory risk level contributed significantly to the model, accounting for $47.5 \%$ of the variance in young adult problematic alcohol use, $\beta=0.68, t(759)=26.2, p<.001 ; F(1,758)=$ $686.9, p<.001$. The addition of marijuana trajectory risk level and tobacco trajectory risk level improved the model, accounting for an additional $3.1 \%$ of the variance in young adult problematic alcohol use, $F(2,756)=23.4, p<.001$. Both marijuana trajectory risk level, $\beta=0.13, t$ (759) $=$ $4.4, p<.001$, and tobacco risk level, $\beta=0.10, t(759)=$ $3.7, p<.001$, contributed significantly beyond the contribution made by the alcohol risk trajectory group. The addition of two-way interactions to the model accounted for an additional $1.6 \%$ of the variance in problematic alcohol use, $F(3,753)=8.3, p<.001$; specifically, interactions between alcohol trajectory risk level and marijuana trajectory risk level, $\beta=-0.23, t(759)=-2.3, p<.05$, and between alcohol trajectory risk level and tobacco trajectory risk level, $\beta=-0.30, t(759)=-3.4, p<.01$, contributed to prediction. In both cases, being part of a high-risk marijuana or tobacco use trajectory increased problematic alcohol use, but only when alcohol trajectory risk level was low. The three-way interaction did not contribute significantly to the model. 


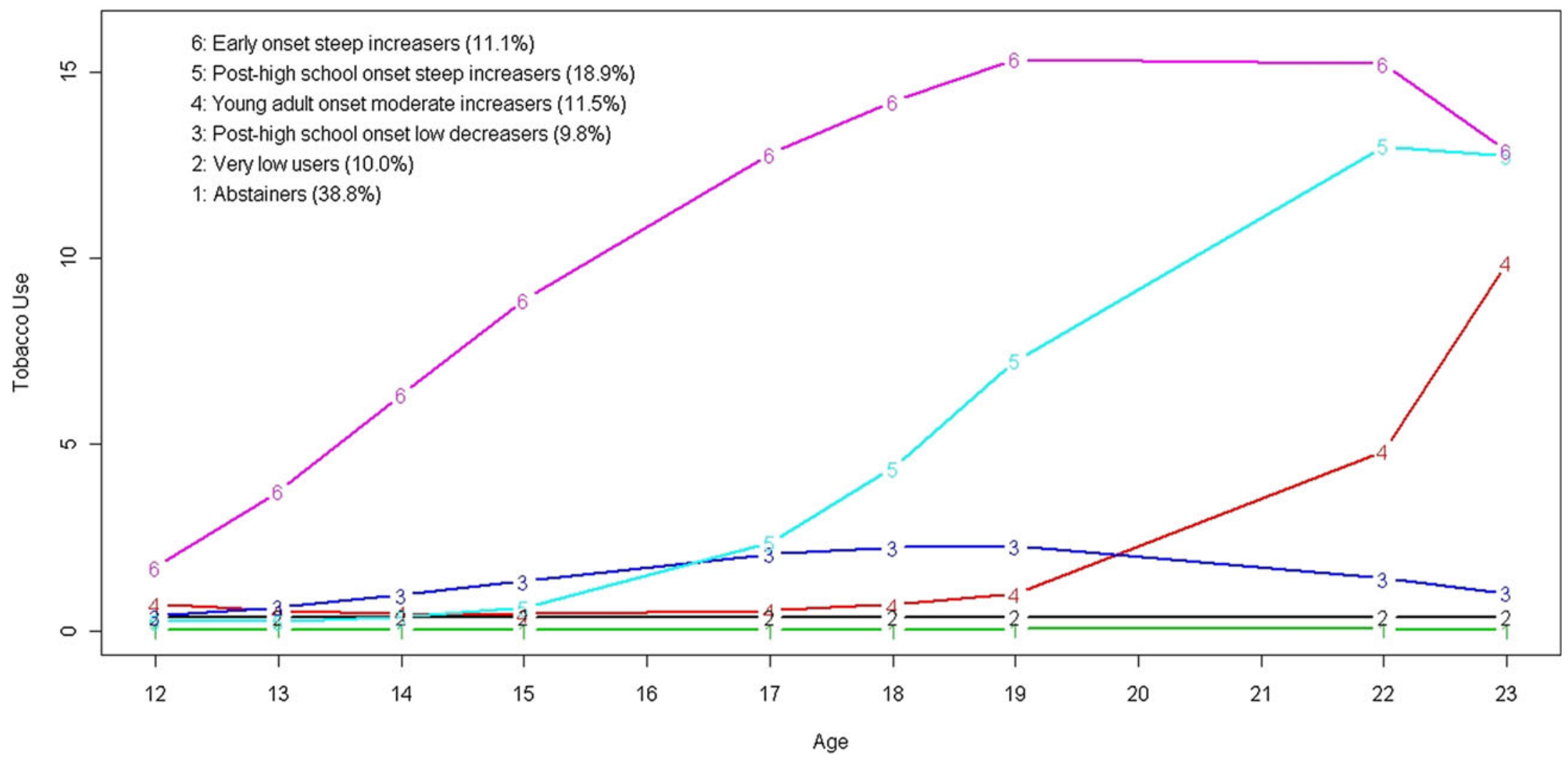

Figure 3. (Color online) Tobacco use trajectories. 
Table 5. Cross-trajectory memberships for marijuana, conditional on alcohol trajectory and tobacco trajectory membership

$\%$ Belonging Each Marijuana Trajectory

1. Abstain. $\quad$ 2. EO Low $\downarrow \quad$ 3. YA Low $\downarrow \quad$ 4. YA Steep $\uparrow \quad$ 5. pHS High $\downarrow \quad$ 6. HS Steep $\uparrow \quad$ 7. EO High $\downarrow$

Alcohol trajectory

1. Abstainers

2. EO low users

3. YA moderate $\uparrow$

4. YA moderate $\downarrow$

5. YA steep $\uparrow$

6. pHS steep $\uparrow$

7. HS steep $\uparrow$

8. EO moderate $\uparrow$

Tobacco trajectory

1. Abstainers

2. Very low users

3. pHS low $\downarrow$

4. YA moderate $\uparrow$

5. pHS steep $\uparrow$

6. EO steep $\uparrow$
33.4

\begin{abstract}
0.0
\end{abstract}

$$
0.0
$$

$21.0 \quad 2.5$

4.2

31.9

6.0

0.0

0.1

25.4

7.5

16.0

23.6

25.0

65.8

9.8

4.8

5.3

10.7

3.7

0.8
6.1
3.4
6.3
32.8
31.9
14.1
4.6

23.1
31.1
7.0
18.0
16.4
4.4

0.0
8.8
4.4
0.0
44.8
13.2
23.6
5.2

3.5
17.1
9.3
38.8
25.6
5.7

2.0
3.2
8.9
14.0
23.8
32.8
5.3
10.1

18.8
6.3
8.8
15.8
41.6
8.7

\section{0}

0.1

0.0

7.0

15.9

24.7

48.5

3.8

4.7

14.0

15.9

8.1

43.4

14.0

$\begin{array}{rrrr}3.1 & 23.1 & 3.5 & 18.8 \\ 14.5 & 31.1 & 17.1 & 6.3 \\ 32.7 & 7.0 & 9.3 & 8.8 \\ 13.4 & 18.0 & 38.8 & 15.8 \\ 8.7 & 16.4 & 25.6 & 41.6 \\ 27.6 & 4.4 & 5.7 & 8.7\end{array}$

Note: EO, Early onset; YA, young adult onset; HS, high school onset; pHS, post-high school onset; $\uparrow$, increasers; $\downarrow$, decreasers.

For problematic marijuana use, marijuana trajectory risk level contributed significantly to the model, accounting for $50.2 \%$ of the variance in young adult problematic marijuana use, $\beta=0.71, t(759)=27.6, p<.001 ; F(1,758)=762.8$, $p<.001$. The addition of alcohol risk level and tobacco trajectory risk level improved the model, accounting for an additional $3.8 \%$ of the variance in young adult problematic marijuana use, $F(2,756)=31.3, p<.001$. Both alcohol trajectory risk level, $\beta=0.17, t(759)=6.4, p<.001$, and to- bacco risk level, $\beta=0.09, t(759)=3.7, p<.001$, contributed significantly beyond the contribution made by the marijuana risk trajectory group. Neither the two-way interactions nor the three-way interaction contributed significantly to the model.

For problematic tobacco use, tobacco trajectory risk level contributed significantly to the model, accounting for $70.5 \%$ of the variance in young adult problematic tobacco use, $\beta=$ $0.84, t(759)=42.6, p<.001 ; F(1,758)=1813.6, p<.001$.

Table 6. Cross-trajectory memberships for alcohol, conditional on marijuana trajectory and tobacco trajectory membership

\begin{tabular}{|c|c|c|c|c|c|c|c|c|}
\hline & \multicolumn{8}{|c|}{$\%$ Belonging to Each Alcohol Trajectory } \\
\hline & 1. Abstain. & $\begin{array}{l}\text { 2. EO Low } \\
\text { Users }\end{array}$ & $\begin{array}{c}\text { 3. YA } \\
\text { Moderate } \uparrow\end{array}$ & $\begin{array}{c}\text { 4. YA } \\
\text { Moderate } \downarrow\end{array}$ & $\begin{array}{l}\text { 5. YA } \\
\text { Steep } \uparrow\end{array}$ & $\begin{array}{l}\text { 6. pHS } \\
\text { Steep } \uparrow\end{array}$ & $\begin{array}{c}\text { 7. HS } \\
\text { Steep } \uparrow\end{array}$ & $\begin{array}{c}\text { 8. EO } \\
\text { Moderate } \uparrow\end{array}$ \\
\hline \multicolumn{9}{|l|}{ Marijuana trajectory } \\
\hline 1. Abstainers & 98.0 & 26.8 & 82.7 & 23.3 & 47.2 & 14.7 & 0.0 & 0.3 \\
\hline 2. EO low $\downarrow$ & 0.0 & 0.0 & 1.2 & 17.3 & 1.4 & 4.9 & 10.0 & 20.5 \\
\hline 3. YA low $\downarrow$ & 1.1 & 24.2 & 6.7 & 17.4 & 24.5 & 39.6 & 24.4 & 15.2 \\
\hline 4. YA steep $\uparrow$ & 0.0 & 16.2 & 4.1 & 0.0 & 15.6 & 7.7 & 19.0 & 8.1 \\
\hline 5. pHS high $\downarrow$ & 0.9 & 3.7 & 5.3 & 11.7 & 5.3 & 12.2 & 2.7 & 10.1 \\
\hline 6. HS steep $\uparrow$ & 0.0 & 0.3 & 0.0 & 9.8 & 6.0 & 15.4 & 42.1 & 6.3 \\
\hline 7. EO high $\downarrow$ & 0.0 & 28.7 & 0.0 & 20.6 & 0.0 & 5.4 & 1.8 & 39.5 \\
\hline \multicolumn{9}{|l|}{ Tobacco trajectory } \\
\hline 1. Abstainers & 90.2 & 8.7 & 61.0 & 27.8 & 34.8 & 24.7 & 0.0 & 0.0 \\
\hline 2. Very low users & 0.0 & 39.5 & 11.4 & 21.0 & 16.6 & $\begin{array}{r}2+1 \\
9.4\end{array}$ & 21.9 & 22.4 \\
\hline 3. pHS low $\downarrow$ & 2.8 & 0.0 & 0.0 & 13.2 & 4.4 & 16.8 & 18.2 & 10.6 \\
\hline 4. YA moderate $\uparrow$ & 0.6 & 13.6 & 7.4 & 16.2 & 17.5 & 13.5 & 8.1 & 14.6 \\
\hline 5. pHS steep $\uparrow$ & 3.6 & 7.0 & 17.1 & 15.9 & 23.3 & 26.7 & 25.0 & 11.1 \\
\hline 6. EO steep $\uparrow$ & 2.8 & 31.2 & 3.1 & 5.8 & 3.4 & 8.9 & 26.8 & 41.2 \\
\hline
\end{tabular}

Note: EO, Early onset; YA, young adult onset; HS, high school onset; pHS, post-high school onset; $\uparrow$, increasers; $\downarrow$, decreasers. 
Table 7. Cross-trajectory memberships for tobacco, conditional on alcohol trajectory and marijuana trajectory membership

\begin{tabular}{|c|c|c|c|c|c|c|}
\hline & \multicolumn{6}{|c|}{$\%$ Belonging to Each Tobacco Trajectory } \\
\hline & 1. Abstain. & 2. Very Low Users & 3. Phs Low $\downarrow$ & 4. YA Moderate $\uparrow$ & 5. pHS Steep $\uparrow$ & 6. EO Steep $\uparrow$ \\
\hline \multicolumn{7}{|l|}{ Alcohol trajectory } \\
\hline 1. Abstainers & 35.7 & 0.0 & 4.5 & 0.7 & 2.7 & 3.5 \\
\hline 2. EO low users & 1.3 & 13.5 & 0.0 & 5.9 & 2.0 & 14.6 \\
\hline 3. YA moderate $\uparrow$ & 16.1 & 6.9 & 0.0 & 5.7 & 8.5 & 2.5 \\
\hline 4. YA moderate $\downarrow$ & 6.9 & 12.0 & 13.5 & 11.7 & 7.4 & 4.5 \\
\hline 5. YA steep $\uparrow$ & 27.6 & 30.1 & 14.2 & 40.5 & 34.5 & 8.6 \\
\hline 6. pHS steep $\uparrow$ & 12.4 & 10.9 & 34.4 & 19.7 & 25.1 & 14.1 \\
\hline 7. HS steep $\uparrow$ & 0.0 & 17.2 & 25.5 & 8.1 & 16.1 & 28.9 \\
\hline 8. EO moderate $\uparrow$ & 0.0 & 9.3 & 7.8 & 7.7 & 3.8 & 23.3 \\
\hline \multicolumn{7}{|l|}{ Marijuana trajectory } \\
\hline 1. Abstainers & 84.9 & 34.7 & 26.6 & 20.9 & 26.4 & 16.4 \\
\hline 2. EO low $\downarrow$ & 0.5 & 6.2 & 21.8 & 6.4 & 2.6 & 14.6 \\
\hline 3. YA low $\downarrow$ & 7.8 & 28.7 & 10.1 & 18.8 & 10.6 & 5.1 \\
\hline 4. YA steep $\uparrow$ & 0.9 & 11.6 & 9.9 & 29.5 & 12.1 & 4.9 \\
\hline 5. pHS high $\downarrow$ & 4.6 & 4.2 & 9.2 & 12.0 & 19.6 & 7.3 \\
\hline 6. HS steep $\uparrow$ & 1.4 & 11.2 & 19.9 & 7.3 & 24.3 & 14.0 \\
\hline 7. EO high $\downarrow$ & 0.0 & 3.5 & 2.5 & 5.1 & 4.3 & 37.7 \\
\hline
\end{tabular}

Note: EO, Early onset; YA, young adult onset; HS, high school onset; pHS, post-high school onset; $\uparrow$, increasers; $\downarrow$, decreasers.

The addition of alcohol trajectory risk level and marijuana trajectory risk level improved the model, accounting for an additional $1.0 \%$ of the variance in young adult problematic tobacco use, $F(2,756)=13.8, p<.001$. However, only alcohol trajectory risk level, $\beta=0.11, t(759)=5.0, p<.001$, contributed significantly beyond the contribution made by the tobacco risk trajectory group; marijuana trajectory risk level was not a significant predictor. Neither the two-way interactions nor the three-way interaction contributed significantly to the model.

\section{Discussion}

Using trajectory modeling, we are able to identify two key features of longitudinal patterns of substance use. The first feature is the timing of onset, and the second is the changing level of use over time.

As would be expected, timing of onset was a key factor for developing problematic substance use by age 22-23, with no onset obviously having the lowest risk, followed in most cases by young adult onset. Earlier in this article we reviewed several studies that revealed robust prediction between early substance use onset and later problematic use. It is likely that this association reflects both contextual and psychological factors. Because use at an age prior to high school is not normative, those who engage likely share psychological and behavioral characteristics, such as impulsivity and risk taking. In addition, specific environmental factors, such as parental and peer substance use, that predict early initiation may also influence growth in use (see Capaldi, Stoolmiller, Kim, \& Yoerger, 2009).

However, in our study, for alcohol, high school and immediate post-high school-onset trajectory members were at similar risk as early-onset trajectory members; for marijuana, timing of onset appeared less important than other trajectory features (i.e., slope). For tobacco, the early-onset users and post-high school increasers were at greatest risk. At least for use that begins prior to young adulthood, it appears that the shape of the trajectories is more important than the timing of onset. For both alcohol and marijuana use, a steep increase in behavior appears to increase risk. For example, individuals who began drinking or using in high school and escalated their behavior quickly had higher levels of problematic use in adulthood than did those who began drinking or using earlier but did not escalate as quickly. For early-onset alcohol and marijuana users, a steep increase predicted higher levels of later problems. For tobacco, trajectory shape predicted problematic use (i.e., steep increasers had more problematic use). Overall, being European American, male, and not attending college increased a person's likelihood of belonging to many of these increasing trajectories. It is important to note that for all three substances, those with steeply increasing trajectories, particularly those centered around high school onset or onset immediately after high school, appear just as vulnerable, if not more vulnerable, to later problems than are those with early-onset trajectories.

For alcohol, only one trajectory exhibited declining use. This young adult-onset trajectory paralleled the other young adult trajectory until the last time point, at which time one trajectory declined and the other increased. To our surprise, the declining trajectory had more problematic use than the other trajectory had. The difference between the young adult-onset, moderate trajectory that increased and the one that declined (i.e., higher levels of disorder among the decliners) might reflect problem awareness. Those who declined did so because they recognized that they were beginning to 
Table 8. Trajectory membership and substance-related outcomes means and standard errors

\begin{tabular}{|c|c|c|c|c|c|}
\hline Model & $B$ & $S E_{B}$ & $\beta$ & $R^{2}$ & $\Delta R^{2}$ \\
\hline \multicolumn{6}{|c|}{ Outcome: age $22-23$ problematic alcohol use } \\
\hline Step 1 & - & - & - & 0.48 & $0.48 * * *$ \\
\hline Alcohol trajectory risk level & 1.60 & 0.06 & $0.69 * * *$ & - & - \\
\hline Step 2 & - & - & - & 0.51 & $0.03 * * *$ \\
\hline Alcohol trajectory risk level & 1.43 & 0.06 & $0.62 * * *$ & - & - \\
\hline Marijuana trajectory risk level & 0.35 & 0.08 & $0.13 * * *$ & - & - \\
\hline Tobacco trajectory risk level & 0.22 & 0.06 & $0.10 * * *$ & - & - \\
\hline Step 3 & - & - & - & 0.52 & $0.02 * * *$ \\
\hline Alcohol trajectory risk level & 2.07 & 0.14 & $0.89 * * *$ & - & - \\
\hline Marijuana trajectory risk level & 0.70 & 0.26 & $0.26^{* *}$ & - & - \\
\hline Tobacco trajectory risk level & 0.53 & 0.14 & $0.25 * * *$ & - & - \\
\hline Alcohol $\times$ Marijuana & -0.15 & 0.07 & $-0.23 *$ & - & - \\
\hline Alcohol $\times$ Tobacco & -0.17 & 0.05 & $-0.30 * *$ & - & - \\
\hline Marijuana $\times$ Tobacco & 0.04 & 0.06 & 0.06 & - & - \\
\hline \multicolumn{6}{|c|}{ Outcome: age $22-23$ problematic marijuana use } \\
\hline Step 1 & - & - & - & 0.50 & $0.50 * * *$ \\
\hline Marijuana trajectory risk level & 1.28 & 0.05 & $0.71 * * *$ & - & - \\
\hline Step 2 & - & - & - & 0.54 & $0.04 * * *$ \\
\hline Marijuana trajectory risk level & 1.10 & 0.05 & $0.61 * * *$ & - & - \\
\hline Alcohol trajectory risk level & 0.26 & 0.04 & $0.17 * * *$ & - & - \\
\hline Tobacco trajectory risk level & 0.14 & 0.04 & $0.10 * * *$ & - & - \\
\hline Step 3 & - & - & - & 0.54 & 0.00 \\
\hline Marijuana trajectory risk level & 1.12 & -0.17 & $0.62 * * *$ & - & - \\
\hline Alcohol trajectory risk level & 0.16 & 0.09 & 0.10 & - & - \\
\hline Tobacco trajectory risk level & 0.23 & 0.09 & $0.17 *$ & - & - \\
\hline Marijuana $\times$ Alcohol & 0.05 & 0.04 & 0.12 & - & - \\
\hline Marijuana $\times$ Tobacco & -0.06 & 0.04 & -0.14 & - & - \\
\hline Alcohol $\times$ Tobacco & 0.01 & 0.03 & 0.02 & - & - \\
\hline \multicolumn{6}{|c|}{ Outcome: age $22-23$ problematic tobacco use } \\
\hline Step 1 & - & & & 0.71 & $0.71 * * *$ \\
\hline Tobacco trajectory risk level & 0.87 & 0.02 & $0.84 * * *$ & - & - \\
\hline Step 2 & - & - & - & 0.72 & $0.01 * * *$ \\
\hline Tobacco trajectory risk level & 0.84 & 0.02 & $0.81 * * *$ & - & - \\
\hline Alcohol trajectory risk level & 0.12 & 0.02 & $0.11 * * *$ & - & - \\
\hline Marijuana trajectory risk level & 0.00 & 0.03 & 0.00 & - & - \\
\hline Step 3 & - & - & - & 0.72 & 0.00 \\
\hline Tobacco trajectory risk level & 0.84 & 0.05 & $0.81 * * *$ & - & - \\
\hline Alcohol trajectory risk level & 0.18 & 0.05 & $0.16^{*}$ & - & - \\
\hline Marijuana trajectory risk level & 0.03 & 0.10 & 0.02 & - & - \\
\hline Tobacco $\times$ Alcohol & -0.01 & 0.02 & -0.04 & - & - \\
\hline Tobacco $\times$ Marijuana & 0.02 & 0.02 & 0.05 & - & - \\
\hline Alcohol $\times$ Marijuana & -0.02 & 0.03 & -0.08 & - & - \\
\hline
\end{tabular}

Note: Step 4, which involved adding the three-way interaction between alcohol, marijuana, and tobacco trajectory risk level, is not included in the table because the interaction did not contribute significantly to any of the models. $* p<.05 . * * p<.01 . * * * p<.001$.

have problems. Declining trajectories are more evident for marijuana use than for alcohol use and do not distinguish particularly problematic use. Four of the marijuana use trajectories were clearly declining, compared with only one alcohol use trajectory. This suggests that individuals age out of marijuana use more than they do alcohol use. For tobacco, it is notable that the two post-high school-onset trajectories differed in shape, with one increasing to high levels of smoking and the other smoking at low to moderate levels and then declining use; in this case, the increasers had higher problematic use scores, likely because the maximum level of use they achieved was greater than that of the other trajectories.
We found that for all substances, membership in the earlyonset trajectories related to education: early-onset users were less likely to attend college within 2 years of graduating high school than were others. For alcohol and tobacco, early-onset users were more likely to be European American than were abstainers. For alcohol and marijuana use, being male predicted membership in the high school-onset trajectories. For marijuana use, individuals who did not receive the study's intervention were more likely to belong to the high school-onset, rapidly escalating trajectory.

Our results share many similarities with those of previous studies but also advance a few new findings. As before, we 
found no/low use trajectories and early-onset trajectories, and they predicted young adult substance use problems (i.e., those in early-onset trajectories were more likely than others to experience problems, and those in the low/no use trajectories were less likely than others to experience problems). In terms of number and type of trajectories, we found more alcohol use and marijuana use trajectories than have most previous studies, but the same number of tobacco use trajectories. It is possible that the greater number of trajectories was an artifact of our methods for trajectory selection. However, the long follow-up period and multiple waves likely allowed for more complex trajectories to emerge. These additional trajectories included rapidly escalating drinking patterns with different onset times (i.e., high school, post-high school, and young adult for alcohol; high school and young adult for marijuana). In addition, they included trajectories with similar onsets but different shapes (i.e., three early-onset trajectories and three young adult-onset trajectories for alcohol; two early-onset and three young adult-onset trajectories for marijuana).

In studies most similar to our own (Flory et al., 2004; Orlando et al., 2005; see Table 1), expected relationships were found between their trajectories and substance use outcomes. In general, nonusers or normative users had better outcomes than did members of late-onset or increasing trajectories, who had better outcomes than early-high or chronic trajectory members. Our findings differed from theirs in terms of the importance of trajectory slope as a risk factor. For alcohol, marijuana, and tobacco use, we found that steeply increasing trajectories that began in high school and even post-high school predicted substance use problems in young adulthood at least as well as early-onset trajectories. These findings can again be explained by the additional complexity in our trajectory models. Because of the large number of trajectories, we were able to compare trajectories with similar onsets but different shapes.

\section{Overlap between trajectories}

The patterns of overlap between trajectories clearly demonstrate that use of the three substances is linked. In particular, marijuana users and tobacco users were likely to use alcohol at some level. Conversely, individuals who abstained from alcohol use were very unlikely to use tobacco and even more unlikely to be marijuana users (i.e., $<2 \%$ ). Tobacco use and marijuana use were less directly linked. Engagement with one substance was not strongly related to engagement with the other. However, across all substances, members of either early-onset trajectories or steeply increasing trajectories had greater likelihood of engaging with other substances at similar levels. The strongest overlap between similar trajectories was for high school-onset use of both alcohol and marijuana.

These results might suggest that alcohol serves as a sort of prerequisite for engagement with marijuana or tobacco. It is possible that individuals who engage in early or frequent alcohol use have more opportunities to engage with other substances, and alcohol thus serves as a gateway drug, as typically defined. However, further investigation of the patterns of overlap between trajectories does not strongly support this conclusion. Though early-onset marijuana users or tobacco users were likely to belong to early-onset alcohol use trajectories, many of them belonged to later onset alcohol use trajectories, suggesting a temporal ordering opposite what one would expect. More likely, whatever risk factors increase a person's vulnerability to engaging with one substance also increase that person's vulnerability to engaging problematically with other substances (see Epstein, Hill, Bailey, \& Hawkins, 2013; Shaffer et al., 2004). The prevalence of alcohol use (i.e., its presence among almost all tobacco and marijuana users despite the converse not being true) would then reflect more its availability and legality than a causal role in the onset of other substance use.

Belonging to more than one high-risk trajectory (e.g., earlyonset alcohol use and early-onset marijuana use) was associated with higher levels of problematic substance use in young adulthood for alcohol, marijuana, and tobacco. These effects were small: membership in a high-risk marijuana or tobacco trajectory increased the variance explained in problematic alcohol use by only $3 \%$ over the variance explained by alcohol use trajectory; for problematic marijuana and tobacco use, inclusion of additional high-risk trajectories increased variance explained by $4 \%$ and $1 \%$, respectively. For problematic alcohol use, significant interactions between substance use trajectories also suggest that belonging to a high-risk marijuana or tobacco use trajectory raises the risk for problematic alcohol use in young adulthood, particularly when an adolescent's alcohol use trajectory was not high risk. These results suggest that high-risk use of one substance might contribute, albeit modestly, to later problems with another substance.

\section{Risk processes}

It appears that the pattern in which youths adopt substance use is linked to their tendency to develop problematic substance use. In contrast to previous research, we find that the steepness of the onset trajectory seems to be the most robust predictor of problematic use. In most cases, there seems to be substance use selection, in that previous use of the same substance predicts later use, with multiple substance use adding statistically significant but relatively small proportions of the variance. For most substance use, underachievement in education, being male, and being European American predict the steepness of the substance use trajectory. Marijuana use in high school was reliably reduced by random assignment to the FCU program. This finding fits with the most recent outcome analyses of the FCU on early-adult substance use, with random assignment associated with less marijuana dependence at age 23 (Véronneau, Dishion, Connell, \& Kavanagh, in press). These findings suggest that engagement of families in early adolescence is critical for reducing the onset trajectories of the most at-risk adolescents.

In some ways, the patterns of onset and the overlap suggest a syndrome perspective on the development of addiction (Shaffer et al., 2004). Youths who steeply increase use of 
one substance are more likely to similarly adopt another substance (especially when marijuana is the focal drug). It is not known whether vulnerability to the rapid increase is secondary to poor self-regulation, genetic vulnerability to the rewarding properties of the drug, or social dynamics that emerge in the context of early drug use. Past research suggests that both poor self-regulation and social dynamics seem to predict escalations from use to dependence. Youths who initiate substance use in adolescence also self-organize into friendship groups that support specific lifestyle congruities, such as partying, substance use, and sexual activity (Dishion \& Owen, 2002; Piehler, Véronneau, \& Dishion, 2012; Van Ryzin \& Dishion, 2014). It has been proposed that self-organization into peer groups based on specific deviant activities is an evolutionary adaptation that is akin to selecting mates that are similar to oneself (Dishion, Ha, \& Véronneau, 2012).

However, it is also true that poor self-regulation seems to add to the influence of peers on substance use escalation and problems. Whether it results from cocreation of a social context that does not motivate self-regulation or a tendency for individuals with low levels of self-regulation to congregate into friendship groups remains unclear. Either way, the results of these trajectory analyses clearly suggest that specifically studying the rate of uptake of substance use patterns in middle adolescence to early adulthood is a key next step in our research agenda. Most studies of substance use examine use at a single point in time. It would be advantageous to use more frequent measurements and study the functional dynamic of substance use as it plays out in youths' active efforts to self-organize an interpersonal world and cope with adversities.

\section{Limitations}

The strengths of this study lie in its longitudinal design, multiple waves of data collection, diverse sample, and high retention rate. However, there are some limitations to the measures and their timing. In the primary measures used to define trajectories, participants are asked about their substance use in the past month. There are three potential limitations of this measure. First, participant recall might not be accurate. Second, because assessments were spaced by at least 1 year, participants' substance-using behavior in the past month might not be representative of their substance-using behavior since the last assessment. Third, using only one item to measure substance use at each time point is not ideal. Patterns of use may differ significantly depending on whether frequency, quantity, or other combinations of variables are measured

\section{References}

Abroms, L., Simons-Morton, B., Haynie, D. L., \& Chen, R. (2005). Psychosocial predictors of smoking trajectories during middle and high school. Addiction, 100, 852-861.

Anthony, J. C. (1991). The epidemiology of drug addiction. In N. S. Miller (Ed.), Comprehensive handbook of drug and alcohol addiction (pp. 5586). New York: Marcel Dekker.
(Jackson \& Sher, 2005). The measure in our study was specific to frequency; it does not provide information about how much individuals consumed on a day on which they used a given substance (e.g., whether they binged or chainsmoked). The study would have benefited from more robust measures of substance-using behavior. In addition, the problematic substance use composites incorporated measures that assessed frequency of use and thus overlapped conceptually with the trajectory-defining measures. Therefore, part of the association between trajectory and problematic substance use was necessarily a result of frequency of use.

\section{Conclusions and future directions}

This study identified trajectories of substance use throughout middle school, high school, and young adulthood, and assessed the relationship among those trajectories and the development of substance use problems. We found that, for both alcohol and marijuana, youths who began using in high school and steeply increased their use had risk for later problems equal to that of youth who began their use much earlier. Although early (i.e., prior to high school) onset of substance use remains a potent predictor of later problems and is potentially indicative of underlying vulnerabilities, high school appears to be another highly vulnerable period for youths. In addition, alcohol use appears to be a common denominator linking youths who use other substances. However, alcohol use does not necessarily precede the use of other substances for these youths, suggesting that it is less a gateway to other substance use and more just an additional expression of a pattern of substance-using behavior.

Although our study found slope and age of onset to be important predictors of later problems, these findings do not establish these trajectory components as causal factors. It is likely that psychosocial factors, such as impulsivity and social setting, for which age of onset is a proxy, carry more causal weight than age of onset itself. Similarly, the shape of a trajectory likely suggests precipitating events or the interaction between psychological and contextual factors that lead to slope changes and consequently to different outcomes. Having identified trajectories and corresponding "markers" (e.g., age of onset and steeply increasing slope), future work must determine what factors are potential causal influences on those trajectories and their markers. In addition, future research must identify what risk factors or transitions discriminate trajectories with similar onset ages but different shapes to determine who is at risk of escalation once substance use begins.

Barnes, G. M., Welte, J. W., Hoffman, J. H., \& Dintcheff, B. A. (2005) Shared predictors of youthful gambling, substance use, and delinquency. Psychology of Addictive Behaviors, 19, 165-174.

Bernat, D. H., Erickson, D. J., Widome, R., Perry, C. L., \& Forster, J. L. (2008). Adolescent smoking trajectories: Results from a populationbased cohort study. Journal of Adolescent Health, 43, 334-340. 
Brook, D. W., Brook, J. S., Zhang, C., Whiteman, M., Cohen, P., \& Finch, S. J. (2008). Developmental trajectories of cigarette smoking from adolescence to the early thirties: Personality and behavioral risk factors. Nicotine and Tobacco Research, 10, 1283-1291.

Brown, T. L., Flory, K., Lynam, D. R., Leukefeld, C., \& Clayton, R. R. (2004). Comparing the developmental trajectories of marijuana use of African American and Caucasian adolescents: Patterns, antecedents, and consequences. Experimental and Clinical Psychopharmacology, $12,47-56$.

Capaldi, D. M., Stoolmiller, M., Kim, H. K., \& Yoerger, K. (2009). Growth in alcohol use in at-risk adolescent boys: Two-part random effects prediction models. Drug and Alcohol Dependence, 105, 109-117.

Chassin, L., Flora, D. B., \& King, K. M. (2004). Trajectories of alcohol and drug use and dependence from adolescence to adulthood: The effects of familial alcoholism and personality. Journal of Abnormal Psychology, 113, 483-498.

Chassin, L., Pitts, S. C., \& Prost, J. (2002). Binge drinking trajectories from adolescence to emerging adulthood in a high-risk sample: Predictors and substance abuse outcomes. Journal of Consulting and Clincial Psychology, 70, 67-78.

Chassin, L., Presson, C. C., Pitts, S. C., \& Sherman, S. J. (2000). The natural history of cigarette smoking from adolescence to adulthood in a midwestern community sample: Multiple trajectories and their psychosocial correlates. Health Psychology, 19, 223-231.

Cleveland, H. H., \& Wiebe, R. P. (2008). Understanding the association between adolescent marijuana use and later serious drug use: Gateway effect or developmental trajectory? Development and Psychopathology, 20, 615-632.

Cloninger, C. R., Bohman, M., \& Sigvardsson, S. (1981). Inheritance of alcohol abuse: Cross-fostering analysis of adopted men. Archives of General Psychiatry, 38, 861-869.

Colder, C. R., Campbell, R. T., Ruel, E., Richardson, J. L., \& Flay, B. R. (2002). A finite mixture model of growth trajectories of adolescent alcohol use: Predictors and consequences. Journal of Consulting and Clinical Psychology, 70, 976-985.

Colder, C. R., Mehta, P., Balanda, K., Campbell, R. T., Mayhew, K. P., Stanton, W. R., et al. (2001). Identifying trajectories of adolescent smoking: An application of latent growth mixture modeling. Health Psychology, 20, 127-135.

Connell, A. M., Dishion, T. J., \& Deater-Deckard, K. (2006). Variable- and person-centered approaches to the analysis of early adolescent substance use: Linking peer, family, and intervention effects with developmental trajectories. Merrill-Palmer Quarterly, 52, 421-448.

Costello, D. M., Dierker, L. C., Jones, B. L., \& Rose, J. S. (2008). Trajectories of smoking from adolescence to early adulthood and their psychosocial risk factors. Health Psychology, 27, 811-818.

DeWit, D. J., Adlaf, E. M., Offord, D. R., \& Ogborne, A. C. (2000). Age at first alcohol use: A risk factor for the development of alcohol disorders. American Journal of Psychiatry, 157, 745-750.

Dishion, T. J., Ha, T., \& Véronneau, M.-H. (2012). An ecological analysis of the effects of deviant peer clustering on sexual promiscuity, problem behavior, and childbearing from early adolescence to adulthood: An enhancement of the life history framework. Developmental Psychology, 48, 703-717.

Dishion, T. J., \& Kavanagh, K. (2000). A multilevel approach to family-centered prevention in schools: Process and outcome. Addictive Behaviors, $25,899-911$.

Dishion, T. J., \& Kavanagh, K. (2003). Intervening with adolescent problem behavior: A family-centered approach. New York: Guilford Press.

Dishion, T. J., Nelson, S. E., \& Bullock, B. M. (2004). Premature adolescent autonomy: Parent disengagement and deviant peer process in the amplification of problem behaviour. Journal of Adolescence, 27, 515-530.

Dishion, T. J., \& Owen, L. D. (2002). A longitudinal analysis of friendships and substance use: Bidirectional influence from adolescence to adulthood. Developmental Psychology, 38, 480-491.

Dishion, T. J., \& Stormshak, E. A. (2007). Intervening in children's lives: An ecological, family-centered approach to mental health care. Washington, DC: American Psychological Association.

Dishion, T. J., Stormshak, E. A., \& Kavanagh, K. (2011). Everyday parenting: A therapist's guide for supporting family management practices. Champaign, IL: Research Press.

Ellickson, P. L., Hays, R. D., \& Bell, R. M. (1992). Stepping through the drug use sequence: Longitudinal scalogram analysis of initiation and regular use. Journal of Abnormal Psychology, 101, 441-451.
Ellickson, P. L., Martino, S. C., \& Collins, R. L. (2004). Marijuana use from adolescence to young adulthood: Multiple developmental trajectories and their associated outcomes. Health Psychology, 23, 299-307.

Ellickson, P. L., Tucker, J. S., \& Klein, D. J. (2003). Ten-year prospective study of public health problems associated with early drinking. Pediatrics, 111(5, Pt. 1), 949-955.

Epstein, M., Hill, K. G., Bailey, J. A., \& Hawkins, J. D. (2013). The effect of general and drug-specific family environments on comorbid and drugspecific problem behavior: A longitudinal examination. Developmental Psychology, 4, 1151-1164.

Flory, K., Lynam, D., Milich, R., Leukefeld, C., \& Clayton, R. (2004). Early adolescent through young adult alcohol and marijuana use trajectories: Early predictors, young adult outcomes, and predictive utility. Development and Psychopathology, 16, 193-213.

Grant, B. F., \& Dawson, D. A. (1998). Age of onset of drug use and its association with DSM-IV drug abuse and dependence: Results from the National Longitudinal Alcohol Epidemiologic Survey. Journal of Substance Abuse, 10, 163-173.

Hawkins, J. D., Graham, J. W., Maguin, E., Abbott, R., Hill, K. G., \& Catalano, R. F. (1997). Exploring the effects of age of alcohol use initiation and psychosocial risk factors on subsequent alcohol misuse. Journal of Studies on Alcohol, 58, 280-290.

Hill, K. G., White, H. R., Chung, I. J., Hawkins, J. D., \& Catalano, R. F. (2000). Early adult outcomes of adolescent binge drinking: Personand variable-centered analyses of binge drinking trajectories. Alcohol: Clinical and Experimental Research, 24, 892-901.

Jackson, K. M., \& Sher, K. J. (2005). Similarities and differences of longitudinal phenotypes across alternate indices of alcohol involvement: A methodologic comparison of trajectory approaches. Psychology of Addictive Behaviors, 19, 339-351.

Jackson, K. M., Sher, K. J., Cooper, M. L., \& Wood, P. K. (2002). Adolescent alcohol and tobacco use: Onset, persistence and trajectories of use across two samples. Addiction, 97, 517-531.

Jackson, K. M., Sher, K. J., \& Schulenberg, J. E. (2005). Conjoint developmental trajectories of young adult alcohol and tobacco use. Journal of $A b$ normal Psychology, 114, 612-626.

Jackson, K. M., Sher, K. J., \& Schulenberg, J. E. (2008). Conjoint developmental trajectories of young adult substance use. Alcohol: Clinical and Experimental Research, 32, 723-737.

Jessor, R. (1987). Problem-behavior theory, psychosocial development, and adolescent problem drinking. British Journal of Addiction, 82, 331-342.

Jessor, R., \& Jessor, S. L. (1977). Problem behavior and psychosocial development: A longitudinal study of youth. New York: Academic Press.

Jones, B. L., \& Nagin, D. S. (2007). Advances in group-based trajectory modeling and an SAS procedure for estimating them. Sociological Methods \& Research, 35, 542-571.

Kandel, D. B., Yamaguchi, K., \& Chen, K. (1992). Stages of progression in drug involvement from adolescence to adulthood: Further evidence for the gateway theory. Journal of Studies on Alcohol, 53, 447-457.

Komro, K. A., Tobler, A. L., Maldonado-Molina, M. M., \& Perry, C. L. (2010). Effects of alcohol use initiation patterns on high-risk behaviors among urban, low-income, young adolescents. Prevention Science, 11, $14-23$.

Lessov-Schlaggar, C. N., Hops, H., Brigham, J., Hudmon, K. S., Andrews, J. A., Tildesley, E., et al. (2008). Adolescent smoking trajectories and nicotine dependence. Nicotine and Tobacco Research, 10, 341-351.

Li, F., Barrera, M. Jr., Hops, H., \& Fisher, K. J. (2002). The longitudinal influence of peers on the development of alcohol use in late adolescence: A growth mixture analysis. Journal of Behavioral Medicine, 25, 293-315.

Li, F., Duncan, T. E., \& Hops, H. (2001). Examining developmental trajectories in adolescent alcohol use using piecewise growth mixture modeling analysis. Journal of Studies on Alcohol, 62, 199-210.

Lynne-Landsman, S. D., Bradshaw, C. P., \& Ialongo, N. S. (2010). Testing a developmental cascade model of adolescent substance use trajectories and young adult adjustment. Development and Psychopathology, 22, 933-948.

Mackesy-Amiti, M. E., Fendrich, M., \& Goldstein, P. J. (1997). Sequence of drug use among serious drug users: Typical vs atypical progression. Drug and Alcohol Dependence, 45, 185-196.

Maggi, S. (2008). Changes in smoking behaviours from late childhood to adolescence: 4 years later. Drug and Alcohol Dependence, 94, 251-253.

Martino, S. C., Ellickson, P. L., \& McCaffrey, D. F. (2009). Multiple trajectories of peer and parental influence and their association with the development of adolescent heavy drinking. Addictive Behaviors, 34, 693-700. 
Metzler, C., Ary, D., \& Biglan, A. (2002). Parenting and family measures: Technical report for the Community Action for Successful Youth (CASY) Project. Eugene, OR: Center for Community Interventions on Childrearing, Oregon Research Institute.

Mezzich, A. C., Tarter, R. E., Feske, U., Kirisci, L., McNamee, R. L., \& Day, B.-S. (2007). Assessment of risk for substance use disorder consequent to consumption of illegal drugs: Psychometric validation of the neurobehavior disinhibition trait. Psychology of Addictive Behaviors, $21,508-515$.

Nagin, D. S. (2005). Group-based modeling of development. Cambridge, MA: Harvard University Press.

Orlando, M., Tucker, J. S., Ellickson, P. L., \& Klein, D. J. (2004). Developmental trajectories of cigarette smoking and their correlates from early adolescence to young adulthood. Journal of Consulting and Clinical Psychology, 72, 400-410.

Orlando, M., Tucker, J. S., Ellickson, P. L., \& Klein, D. J. (2005). Concurrent use of alcohol and cigarettes from adolescence to young adulthood: An examination of developmental trajectories and outcomes. Substance Use and Misuse, 40, 1051-1069.

Piehler, T. F., Véronneau, M.-H., \& Dishion, T. J. (2012). Substance use progression from adolescence to early adulthood: Effortful control in the context of friendship influence and early-onset use. Journal of Abnormal Child Psychology, 40, 1045-1058.

Riggs, N. R., Chou, C. P., Li, C., \& Pentz, M. A. (2007). Adolescent to emerging adulthood smoking trajectories: When do smoking trajectories diverge, and do they predict early adulthood nicotine dependence? Nicotine and Tobacco Research, 9, 1147-1154.

Robins, L. N., \& Przybeck, T. R. (1985). Age of onset of drug use as a factor in drug and other disorders. NIDA Research Monographs, 56, 178-192.

Schulenberg, J. E., Merline, A. C., Johnston, L. D., O’Malley, P. M., Bachman, J. G., \& Laetz, V. B. (2005). Trajectories of marijuana use during the transition to adulthood: The big picture based on national panel data. Journal of Drug Issues, 35, 255-279.

Schulenberg, J. E., Wadsworth, K. N., O'Malley, P. M., Bachman, J. G., \& Johnston, L. D. (1996). Adolescent risk factors for binge drinking during the transition to young adulthood: Variable and pattern-centered approaches to change. Developmental Psychology, 32, 659-674.

Shaffer, H. J., LaPlante, D. A., LaBrie, R. A., Kidman, R. C., Donato, A. N., \& Stanton, M. V. (2004). Toward a syndrome model of addiction: Multiple expressions, common etiology. Harvard Review of Psychiatry, 12, 367-374.
Tarter, R. E., Horner, M., \& Ridenour, T. (2012). Developmental perspective of substance use disorder etiology. In H. J. Shaffer, D. A. LaPlante, \& S. E. Nelson (Eds.), The APA addiction syndrome handbook: Vol. 1. Foundations, influences, and expressions of addiction (pp. 261-287). Washington, DC: American Psychological Association Press.

Tarter, R. E., Kirisci, L., Mezzich, A., Cornelius, J., Pajer, K., Vanyukov, M., et al. (2003). Neurobehavioral disinhibition in childhood predicts early age at onset of substance use disorder. American Journal of Psychiatry, 160, 1078-1085.

Van Ryzin, M. J., \& Dishion, T. J. (2013). From antisocial behavior to violence: A model for the amplifying role of coercive joining in adolescent friendships. Journal of Child Psychology and Psychiatry, 54, 661-669.

Van Ryzin, M. J., \& Dishion, T. J. (2014). Adolescent deviant peer clustering as an amplifying mechanism underlying the progression from early substance use to late adolescent dependence. Journal of Child Psychology and Psychiatry. Advance online publication.

Véronneau, M.-H., Dishion, T. J., Connell, A. M., \& Kavanagh, K. (in press). Long-term outcomes of the Family Check-Up model in public secondary schools: A randomized clinical trial linking parent engagement to the progression of substance use from early adolescence to adulthood. Journal of Consulting and Clinical Psychology.

Wallace, J. M. Jr., Bachman, J. G., O'Malley, P. M., Schulenberg, J. E., Cooper, S. M., \& Johnston, L. D. (2003). Gender and ethnic differences in smoking, drinking and illicit drug use among American 8th, 10th and 12th grade students, 1976-2000. Addiction, 98, 225-234.

Wanner, B., Vitaro, F., Ladouceur, R., Brendgen, M., \& Tremblay, R. E. (2006). Joint trajectories of gambling, alcohol and marijuana use during adolescence: A person- and variable-centered developmental approach. Addictive Behaviors, 31, 566-580.

White, H. R., Pandina, R. J., \& Chen, P. H. (2002). Developmental trajectories of cigarette use from early adolescence into young adulthood. Drug and Alcohol Dependence, 65, 167-178.

Windle, M., Mun, E. Y., \& Windle, R. C. (2005). Adolescent-to-young adulthood heavy drinking trajectories and their prospective predictors. Journal of Studies on Alcohol, 66, 313-322.

Windle, M., \& Wiesner, M. (2004). Trajectories of marijuana use from adolescence to young adulthood: Predictors and outcomes. Development and Psychopathology, 16, 1007-1027. 